•研究报告・

\title{
云南高黎贡山地区蝴蝶群落多样性
}

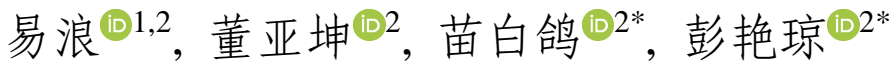

1. 云南大学生态学与环境学院, 昆明 650091; 2. 中国科学院西双版纳热带植物园, 云南预腊 666303

摘要: 位于滇西北的高黎贡山是全球生物多样性研究和保护的热点地区之一, 然而该地区昆虫多样性缺乏系统调查和总结。 本研究聚焦蝴蝶类群, 考虑该区域高山峡谷特点, 结合海拔梯度、生境类型和季节变化, 采用样线法调查、分析蝴蝶物种多 样性及群落结构变化。结果显示: 共观测记录到蝴蝶2,055只, 隶属于5科85属151种, 在历史记录上新增27种, 使该地区已知 蝴蝶种类达 488 种; 其中蛱蝶科物种多样性最高, 灰蝶科次之, 凤蝶科最低。蝴蝶群落多样性分析结果表明: 中海拔 1,000-2,000 m区域种类丰富、多样性指数最高; 低海拔区蝴蝶分布明显聚集，并且与高海拔地区空间上分离，少有重叠。该 地区不同生境中蝴蝶的种类及数量差异也较大, 物种数及多样性指数在自然保护区最高、边缘交错带居中及农业种植区最 低。此外, 蝴蝶的种类和数量也存在季节差异, 春季调查到的个体数少, 夏季观察到的物种数少, 两年秋季调查到的物种丰富 度、多样性均高, 但存在季节内变化。总之, 高黎贡山地区不同海拔、生境、季节间和季节内蝴蝶群落组成有自身特点, 共 存物种有限, 蝴蝶群落相似性低。综合评估分布于该地区的蝴蝶保护种类, 包括易危种 17 种、近危种 50 种, 有国家二级保护 蝴蝶3种。本研究弄清了高黎贡山地区蝴蝶的物种本底, 并调查获得其多样性随海拔、生境和季节变化的模式, 为加强区域物 种多样性监测、保护生物多样性提供了科学依据。

关键词: 高黎贡山; 蝴蝶; 物种多样性; 群落结构; 海拔; 生境; 季节

易浪, 董亚坤, 苗白鸽, 彭艳琼 (2021) 云南高黎贡山地区蝴蝶群落多样性. 生物多样性, 29, 950-959. doi: 10.17520/biods.2020486.

Yi L, Dong YK, Miao BG, Peng YQ (2021) Diversity of butterfly communities in Gaoligong region of Yunnan. Biodiversity Science, 29, 950-959. doi: 10.17520/biods.2020486.

\section{Diversity of butterfly communities in Gaoligong region of Yunnan}

Lang $\mathrm{Yi}^{(1,2}$, Yakun Dong ${ }^{(12}$, Baige Miao ${ }^{\left({ }^{2 *}\right.}$, Yanqiong Peng ${ }^{(12 *}$

1 College of Ecology and Environmental Science, Yunnan University, Kunming 650091

2 Xishuangbanna Tropical Botanical Garden, Chinese Academy of Sciences, Mengla, Yunnan 666303

\section{ABSTRACT}

Aims: Gaoligong is located in northwest Yunnan, a mountainous biodiversity hotspot in Southwest China. In this region, insect diversity has not been systematically investigated or summarized.

Methods: We focused on investigating butterfly diversity using a 1-km transect method at different altitudes, habitats and seasons in Gaoligong region.

Results: A total of 2,055 butterflies were recorded, belonging to 5 families, 85 genera, and 151 species. Of these, 27 species were recorded for the first time, increasing the total number of recorded butterfly species in Gaoligong to 488 species. Among the five families, the Nymphalidae had the highest species diversity, followed by Lycaenidae, while Hesperiidae had the lowest. The species diversity of butterflies showed the greatest abundance and highest richness at the 1,000-2,000 m altitude. At low elevations species were concentrated, and there was little overlap of species with those at higher elevations. The species and individuals of butterflies in different habitats were also different, the diversity was higher in the nature reserve, followed by the ecotone, and was lowest in the farm area. Additionally, diversity and abundance varied seasonally, with the lowest abundance observed in spring and the lowest diversity in summer, both diversity and abundance were the highest in autumns of two years, but exhibited intra-seasonal variation. Overall, the community composition of butterflies had distinct characteristics at different altitudes, habitats and seasons,

收稿日期: 2020-12-30; 接受日期: 2021-04-02

基金项目: 生态环境部生物多样性调查评估项目(2019HJ2096001006)

* 共同通讯作者 Co-authors for correspondence. E-mail: miaobaige@xtbg.org.cn; pengyq@xtbg.ac.cn 
only a few species were shared between communities and the community similarity of butterflies was found to be low. The butterflies were comprehensively evaluated in Gaoligong region, including 17 vulnerable species, 50 near-threatened species, and 3 species that were listed as second class protection animals in China.

Conclusion: This study systematically identified the species of butterflies in Gaoligong region, and obtained the diversity pattern of butterfly communities within different altitudes, habitats and seasons. The results will provide the scientific basis for strengthening regional species monitoring and biodiversity conservation.

Key words: Gaoligong region; butterfly; species diversity; community structure; altitude; habitat; season

蝴蝶作为森林和农业生态系统中的主要传粉 媒介(DeVries et al, 1997), 是生物资源的重要组成 部分(Samways, 2005)。全球已记载蝴蝶2万多种, 我 国有2,100余种，占世界种数的10\% (武春生和徐堉 峰, 2017)。自20世纪以来, 蝴蝶多样性的监测和研 究一直倍受关注 (Prendergast \& Eversham, 1995; Habel et al, 2016; Agarwala \& Majumder, 2020)。蝴蝶 分布广、白天活动、物种多样性高, 易于识别与鉴 定 (Thomas, 2005; 马方舟等, 2018; 李欣芸等, 2020); 在全球变化和生境退化日益加剧的背景下, 蝴蝶因对环境变化敏感, 已成为监测与评价栖息地 环境变化的首选指示物种 (Nowicki et al, 2008; Kumar et al, 2009; Forister et al, 2010; Basset et al, 2017)。2016年原环境保护部启动了全国蝴蝶多样性 观测并建立了全国蝴蝶观测网络(马方舟等, 2018), 包括了云南哀牢山、壶瓶山、齐云山等多个国家级 自然保护区, 为全国蝴蝶物种多样性的研究奠定了 良好的基础(邓敏等, 2020; 黄敦元等, 2020; 王群等, 2020)。

目前, 从森林生态系统到农田生态系统, 调查 蝴蝶群落多样性并分析其影响因素的研究较多 (Chettri, 2015; Sánchez-Fernández et al, 2020; Miao et al, 2020; Sharma et al, 2020), 但大多数研究集中 于分析生境差异和气候因子对蝴蝶多样性的影响 (贺奇等, 2019; Miao et al, 2020; Sánchez-Fernández et al, 2020), 如海拔变化可显著改变蝴蝶的丰富度 (Leingärtner et al, 2014); 季节变化也是影响蝴蝶群 落时空分布格局的决定因素, 与湿润季节相比, 干 季有更高的物种多样性(Hamer et al, 2005; Arya et al, 2020)。

云南西北部的高黎贡山地处印度板块和欧亚 板块相碰撞及板块俯冲的缝合线地带, 其地理位置 独特, 区域内动物种类众多, 南北混杂, 东西过渡, 是青藏高原和中南半岛的南北生物走廊, 是亚热
带、温带、寒温带野生动植物种质基因库, 是全球 生物多样性热点地区之一(Myers et al, 2000; 陈奕 欣等, 2016)。高黎贡山地区已知植物 5,139种, 其中 中国特有种1,163种(李恒和李嵘, 2020); 在部分地 区观测到繁殖鸟类277种, 以及红外相机监测到兽 类18种(高歌等, 2017; Pan et al, 2019); 但对种类繁 多的昆虫的研究报道却非常有限(杨平之等, 2016; Liu et al, 2020), 特别是传粉昆虫的研究。前人在怒 江峡谷、高黎贡山百花岭及南部边缘一带开展过蝴 蝶资源的调查, 有零散的报道(董大志等, 2002; 刘 莉和高焕平, 2014; 刘莉, 2016)。本研究根据高黎贡 山地区高山峡谷、垂直自然景观和立体气候特点, 研究蝴蝶群落的多样性, 主要回答3个问题: (1)高 黎贡山地区的蝴蝶物种多样性现状; (2)该地区蝴蝶 群落多样性随海拔梯度、生境类型及季节的变化规 律; (3) 该地区蝴蝶濒危、保护物种的评估, 以期为 高黎贡山地区蝴蝶多样性的监测和保护提供科学 依据。

\section{研究区域与研究方法}

\section{1 研究区域概况}

高黎贡山位于滇西北、青藏高原南部的横断山 脉西部断块带, 属于典型的亚热带气候, 年均温 $14.7^{\circ} \mathrm{C}, 1$ 月最冷, 8 月最热, 年降水量东西坡虽有差 异, 但均在 $3,000 \mathrm{~mm}$ 以上; 具有北段冷、中段温暖、 南段热, 高山寒冷、半山温暖、江边炎热的独特气 候。高黎贡山区域涉及保山市隆阳区、腾冲县, 以 及怒江州的沪水县、福贡县及贡山县 5 个区县; 高黎 贡山国家级自然保护区位于 $24^{\circ} 56^{\prime}-28^{\circ} 22^{\prime} \mathrm{N}$, $98^{\circ} 08^{\prime}-98^{\circ} 50^{\prime} \mathrm{E}$, 总面积 405,549 ha, 该地为高山峡 谷, 具有垂直、立体的植被类型及气候, 生物资源 十分丰富(Dumbacher et al, 2011; Liu et al, 2020)。查 阅已出版的文献、书籍及馆藏标本信息, 获得已记 录分布于高黎贡山地区的蝴蝶种类461种(附录1), 
隶属于 5 科 182 属, 包括文献记录426种(董大志等, 2002; 欧晓红等, 2005; 刘莉和高焕平, 2014; 武春 生和徐垤峰, 2017)和馆藏标本35种; 其中蛱蝶科种 类最多，占 $53 \%$, 灰蝶科和弄蝶科各占 $15 \%$ 、粉蝶科 占 $10 \%$, 最少的是凤蝶科, 仅占 $7 \%$ 。

\section{2 研究方法}

\subsection{1 调查方法}

2019年9月至2020年10月, 在高黎贡山南段东 坡百花岭一带、西坡滕冲县界头镇, 中段沪水至片 马镇沿线、福贡十八里沿线, 以及北段贡山至独龙 江马库、贡山至丙中洛及贡山至孔雀山隧道沿线, 沿公路、小径、步道共设置调查样线127条, 每条样 线长 $1 \mathrm{~km}$, 将各样线编号标记并记录每条样线上的 生境类型, 用GPS定位仪测定坐标, 在1:10000地图 上标注样线轨迹。选择晴朗的天气或者阴天温度高 于 $17^{\circ} \mathrm{C}$ 时, 采用样线法调查蝴蝶种类及数量, 行进 速度为 $1.5 \mathrm{~km} / \mathrm{h}$, 记录样线左右各 $2.5 \mathrm{~m}$ 、上方 $5 \mathrm{~m}$ 范 围见到的所有蝴蝶的种类、数量、活动状态, 并拍 摄其生态照片。对于观测中难以确定的物种, 采集 标本, 用三角纸袋包装好并且记录其个体数量, 带 回实验室进行标本制作、分类鉴定(武春生和徐垤峰, 2017)。

样线调查时综合考虑不同海拔、不同生境及不 同季节。将观测区海拔 $(638-3,144 \mathrm{~m})$ 分为低 $(<1,000$ $\mathrm{m}) 、$ 中 $(1,000-2,000 \mathrm{~m})$ 和高 $(>2,000 \mathrm{~m}) 3$ 个梯度。此 外, 该地区从山谷热带季雨林到山顶高山草甸, 植 被类型垂直分布格局非常明显，依据植被类型将生 境划分为保护区、边缘交错带和农业种植区3类。 在2019年秋季(9月)、2020年春季(3月)、夏季(6月) 及秋季(9月)分别开展了不同季节的调查, 调查样线 及分布见附录 2 。

\subsection{2 蝴蝶群落 $\alpha$ 和 $\beta$ 多样性分析}

调查到的蝴蝶种类和数量, 使用基于希尔数 $\mathrm{q}$ 的渐近多样性估计, 比较不同海拔、生境、季节中 蝴蝶群落的 $\alpha$ 多样性。希尔将物种的丰富度(species richness)和相对丰富度(species relative abundance)整 合为一类多样性测度指标, 被称为希尔数 (Hill numbers)或有效物种数(effective numbers of species) (Hill, 1973)。相比其他的多样性测度指标, 希尔数 在统计上更加严谨(Chao et al, 2014a)。

使用基于实际采样的个体数和物种数关系进 行稀疏外推的R软件iNEXT程序包(Hsieh et al, 2016)
计算物种丰富度 $(\mathrm{q}=0)$ 、Shannon多样性 $(\mathrm{q}=1)$ 和 Simpson多样性 $(q=2)$; 物种丰富度 $(q=0)$ 只关注物 种存在与否, 平等地计数物种而不考虑它们的相对 丰度，值越大表明群落中物种越丰富; Shannon多样 性 $(\mathrm{q}=1)$ 按物种丰度的比例计数来估计, 可解释为 群落中常见物种的有效数量; Simpson多样性 $(\mathrm{q}=2)$ 通过优势种计数来估计, 反映群落中优势种的有效 数量。采用95\%置信区间的200次Bootstrap重抽样的 方法估计蝴蝶群落的 $\alpha$ 多样性(Chao et al, 2014a, b, 2020; Chai \& Wang, 2016)。为了评估不同因素(包括 3 个海拔梯度、3类生境及 4 个季节)蝴蝶群落组成的 $\beta$ 多样性，基于不同因子水平下的物种丰富度，使用 R 软件betapart程序包(Baselga，2013)进行了非度量 多维尺度分析(nMDS) (Oksanen et al, 2019)。nMDS 是一种基于排名的方法, 用各位点的相互距离反映 不同海拔、生境、季节各水平之间蝴蝶群落组成的 差异。

\subsection{3 蝴蝶群落相似性分析}

使用 R软件 circlize程序包绘制样本-群落构成 关联弦状图，量化不同海拔、生境和季节之间的蝴 蝶共有物种数, 比较不同因素水平间的Jaccard群落 相似性指数 $\left(C_{\mathrm{s}}\right)$ 是否具有差异, 公式为: $C_{\mathrm{s}}=c /(a+b$ $-c$ ) (Kitahara \& Sei, 2001)。式中, $a$ 为A群落物种数, $b$ 为B群落物种数, $c$ 为 $\mathrm{A} 、 \mathrm{~B}$ 两群落共有的物种数。 定义 $C_{\mathrm{s}}$ 为 $0-0.25$ 时为极不相似, $0.25-0.50$ 时为中等 不相似, $0.50-0.75$ 时为中等相似, $0.70-1.00$ 时为极 相似。

\section{结果}

\section{1 蝴蝶群落的物种多样性}

本研究共记录蝴蝶 2,055 只, 隶属于 5 科 85 属 151种(附录3)。在科级水平上, 不同科物种组成有差 异，蛱蝶科有31属63种，其物种丰富度、Shannon指 数和Simpson指数均最高; 灰蝶科的多样性指数次 之; 凤蝶科的多样性指数均最低; 粉蝶科与弄蝶科 的多样性指数居中, 且粉蝶科仅物种丰富度比弄蝶 科高(表1)。

\section{2 不同海拔蝴蝶群落多样性变化}

不同海拔区域蝴蝶群落多样性有明显的差异。 在1,000-2,000 m的中海拔地区观测到106种蝴蝶, 其物种丰富度、Shannon指数和Simpson指数均最高 (表2), 说明该海拔范围内蝴蝶物种丰富, 多样性最 
表1 云南高黎贡山地区蝴蝶群落多样性指数(平均值 \pm 标准误)

Table 1 Diversity indices of butterfly communities in Gaoligong region of Yunnan (mean $\pm \mathrm{SE}$ )

\begin{tabular}{llllll}
\hline $\begin{array}{l}\text { 科名 } \\
\text { Family }\end{array}$ & $\begin{array}{l}\text { 属数 } \\
\text { No. of genus }\end{array}$ & $\begin{array}{l}\text { 个体数 } \\
\text { No. of individuals }\end{array}$ & $\begin{array}{l}\text { 物种丰富度 } \\
\text { Species richness }\end{array}$ & $\begin{array}{l}\text { Shannon指数 } \\
\text { Shannon index }\end{array}$ & $\begin{array}{l}\text { Simpson指数 } \\
\text { Simpson index }\end{array}$ \\
\hline 粉蝶科 Pieridae & 10 & 945 & $23 \pm 3.39$ & $9.03 \pm 0.34$ & $6.05 \pm 0.26$ \\
凤蝶科 Papilionidae & 5 & 129 & $10 \pm 3.72$ & $4.13 \pm 0.52$ & $2.57 \pm 0.30$ \\
灰蝶科 Lycaenidae & 29 & 416 & $44 \pm 17.86$ & $20.09 \pm 1.34$ & $13.67 \pm 0.94$ \\
蛱蝶科 Nymphalidae & 31 & 549 & $63 \pm 12.20$ & $26.25 \pm 1.66$ & $15.50 \pm 1.06$ \\
弄蝶科 Hesperiidae & 10 & 16 & $11 \pm 7.79$ & $10.04 \pm 5.73$ & $9.14 \pm 6.18$ \\
\hline
\end{tabular}

表2 云南高黎贡山地区不同海拔、生境和季节蝴蝶群落的多样性(平均值 \pm 标准误)

Table 2 Diversity indices of butterfly communities in different altitudes, habitats and seasons in Gaoligong region of Yunnan (mean $\pm \mathrm{SE}$ )

\begin{tabular}{llllll}
\hline 因素 & & $\begin{array}{l}\text { 个体数 } \\
\text { Fo. of individuals }\end{array}$ & $\begin{array}{l}\text { 物种丰富度 } \\
\text { Species richness }\end{array}$ & $\begin{array}{l}\text { Shannon指数 } \\
\text { Shannon index }\end{array}$ & $\begin{array}{l}\text { Simpson指数 } \\
\text { Simpson index }\end{array}$ \\
\hline 海拔 & $<1,000$ & 887 & $63 \pm 26.54$ & $17.46 \pm 1.08$ & $8.13 \pm 0.52$ \\
Altitude $(m)$ & $1,000-2,000$ & 1,020 & $106 \pm 20.89$ & $40.59 \pm 1.90$ & $21.87 \pm 1.44$ \\
& $>2,000$ & 148 & $38 \pm 10.97$ & $21.93 \pm 2.77$ & $14.11 \pm 2.12$ \\
生境 & 保护区 Reserve & 375 & $83 \pm 19.93$ & $45.81 \pm 3.37$ & $30.07 \pm 2.49$ \\
Habitat & 边缘交错带 Ecotone & 659 & $80 \pm 9.68$ & $38.44 \pm 1.92$ & $23.88 \pm 1.43$ \\
& 农业种植区 Farm & 1,021 & $75 \pm 30.83$ & $22.25 \pm 1.02$ & $11.59 \pm 0.73$ \\
季节 & 2019秋季 Autumn & 977 & $99 \pm 38.64$ & $28.00 \pm 1.54$ & $12.64 \pm 0.88$ \\
Season & 2020春季 Spring & 271 & $49 \pm 5.29$ & $19.11 \pm 1.93$ & $8.66 \pm 1.10$ \\
& 2020夏季 Summer & 338 & $42 \pm 11.67$ & $18.10 \pm 1.36$ & $10.62 \pm 1.07$ \\
& 2020秋季 Autumn & 469 & $67 \pm 11.62$ & $38.16 \pm 2.09$ & $26.70 \pm 1.73$ \\
\hline
\end{tabular}

高。在2,000-3,000 m的高海拔区域, 调查到的蝴蝶 种类和个体数最少, 但其Shannon指数和Simpson指 数大小均居中; 而在海拔 $1,000 \mathrm{~m}$ 以下, 除了物种丰 富度较高外, Shannon指数和Simpson指数均最低(图 1 )。从 $\beta$ 多样性的空间分布格局看, 低海拔地区观测 到的种类明显聚集, 与高海拔地区空间上分离, 少 有重叠, 仅在低海拔区观测到的有达摩凤蝶 (Papilio demoleus)、优越斑粉蝶(Delias hyparete)、 凯丽藤灰蝶(Tarucus callinara)等24种; 高海拔地区 观测到的种类空间上分散, 仅分布于高海拔地区的 有迷纹黛眼蝶(Lethe maitrya)、黑绢斑蝶(Parantica melanea)、华山黛眼蝶(Lethe serbonis)等19种。分布 于中海拔区域的蝴蝶一部分种类向下与低海拔区 域的物种交叉分布, 另有部分蝴蝶种类向上与高海 拔区域的物种重叠分布, 能观测到多尾凤蝶 (Bhutanitis lidderdalii)和方裙褐蚬蝶(Abisara freda) 等珍稀蝶类, 也能观察到橙黄豆粉蝶(Colias fieldii) 和柑橘凤蝶(Papilio xuthus)等农业害虫。

\section{3 不同生境蝴蝶群落多样性的变化}

在高黎贡山保护区、边缘交错带和农业种植区 三类生境中, 蝴蝶多样性组成有显著差异，保护区 中物种丰富度、Shannon指数和Simpson指数均最高; 边缘交错带 3 个多样性指数大小居中; 农业种植区 个体数量最多, 但各多样性指数均最低(表 2$) \circ \beta$ 多样 性空间分布格局显示: 农业种植区观测到的种类分 布较集中, 保护区和边缘交错带的蝴蝶种类分布较 散; 农业种植区和保护区中的蝴蝶种类很少有重叠, 边缘交错带则与其他两种生境中蝴蝶有部分交叉、 重叠分布(图1)。不同生境均有特有的蝴蝶种类, 如 保护区中有百娆灰蝶(Arhopala bazala)、依彩灰蝶 (Heliophorus eventa)、黑绢斑蝶等40种; 边缘交错区 中有幽㬦眼蝶 (Ypthima conjuncta)、拟稻眉眼蝶 (Mycalesis francisca)、幻紫斑蛱蝶 (Hypolimnas bolina) 等 24 种; 农业种植区有鹿灰蝶 (Loxura atymnus)、优越斑粉蝶、黄裳眼蛱蝶(Junonia hierta) 等29种。 

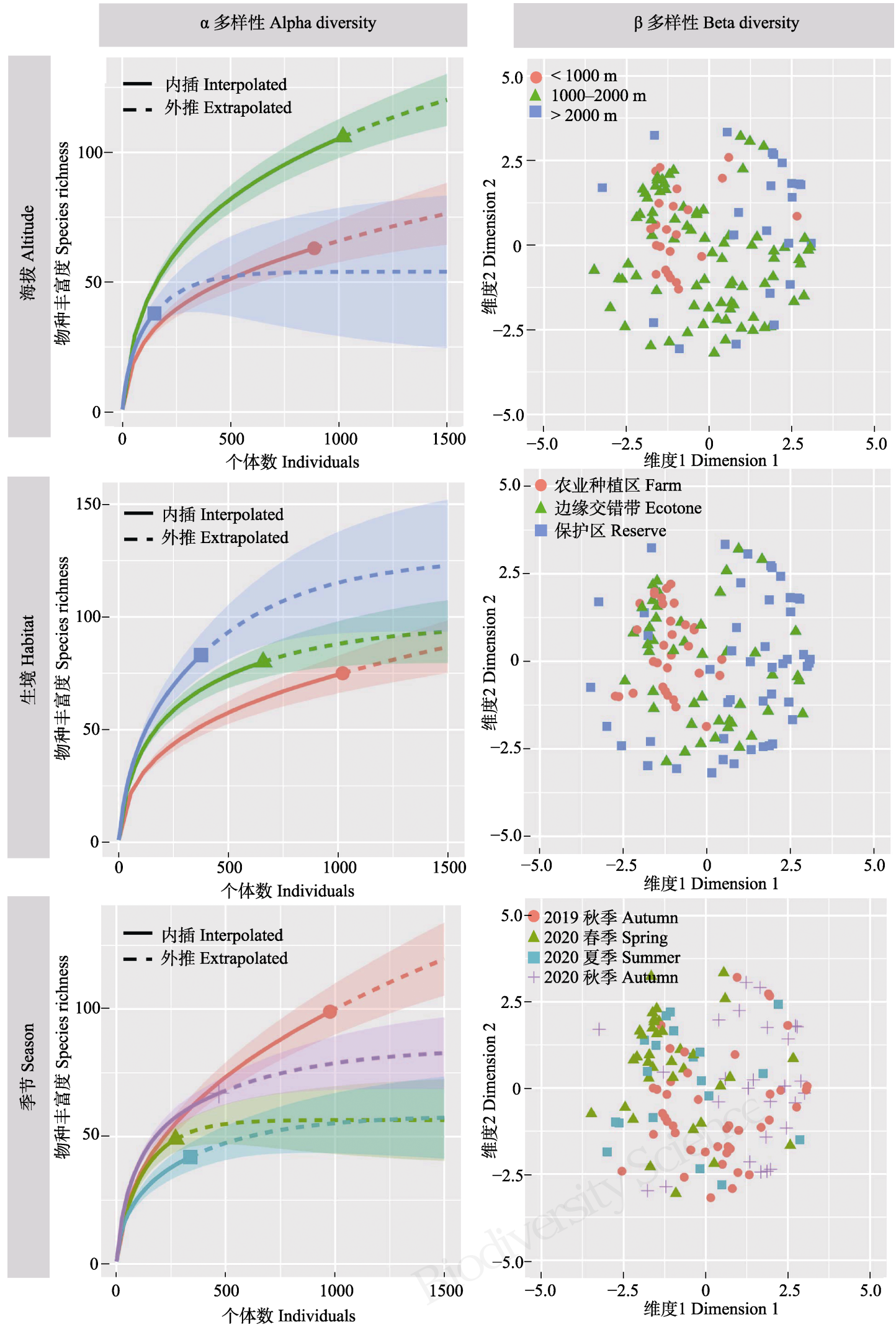

图1 高黎贡山地区不同海拔、生境、季节蝴蝶群落 $\alpha$ 和 $\beta$ 多样性

Fig. 1 Alpha and beta diversity patterns of butterfly communities among different altitudes, habitats, seasons in Gaoligong region 


\section{4 不同季节蝴蝶群落多样性的变化}

春季调查到 49 种蝴蝶, 但个体数量最少; 夏季 降雨较多, 种数最少, 个体数较多; 2019和2020年 两年秋季调查到的蝴蝶种类和数量都最多。总体上 秋季蝴蝶群落的物种丰富度、Shannon指数和 Simpson指数均最高; 春季物种丰富度和Shannon指 数次之, 夏季仅Simpson指数比春季高, 显示夏季 优势种的数量较多(表2)。从 $\beta$ 多样性的空间分布格 局看, 秋季各点明显分散, 季节内物种分布重叠度 高, 并且与春、夏季的蝴蝶种类少有重叠。春、夏 季的蝴蝶种类交叉分布, 没有明显的分离(图1)。仅 在春季观测到的蝴蝶有尖角黄粉蝶(Eurema laeta)、 鹤顶粉蝶(Hebomoia glaucippe)、锯灰蝶(Orthomiella pontis)等14种; 夏季发生的蝴蝶种类与春季或秋季 重叠; 在秋季共观测到蝴蝶128种, 只出现在秋季 的有81种, 两年秋季观察到90种不同的蝴蝶。结果 表明蝴蝶群落多样性不仅呈现季节间差异, 也存在 季节内变化(表2)。

\section{5 不同海拔、生境和季节蝴蝶群落的相似性分析}

在不同海拔、生境和季节中, 一些适应性强、 分布广的种类可重叠分布; 3 个海拔梯度中共享的 蝴蝶种类有小环蛱蝶 (Neptis sappho)、波蛱蝶 (Ariadne ariadne)、翠蓝眼蛱蝶(Junonia orithya)、异 型紫斑蝶(Euploea mulciber)和东方菜粉蝶(Pieris canidia) 5 种; 其中在低海拔和中海拔共享有 37 种蝴 蝶, 中海拔和高海拔地区共享17种蝴蝶, 低海拔和 高海拔地区仅共享 7 种蝴蝶。不同海拔蝴蝶群落相 似性系数分别是低中海拔间 0.28 、低高海拔间 0.07 , 以及中高海拔间 0.13 , 结果显示在不同海拔梯度上 虽然共享部分蝴蝶种类，但群落之间极不相似。

在高黎贡山自然保护区、边缘交错带及农业种 植区三种生境中共享29种蝴蝶, 其中边缘交错带与 农业种植区共享的物种数最多, 为 44 种, 保护区和 边缘交错带共享物种数为 41 种, 保护区和农业种植 区共享31种。蝴蝶群落相似性系数分别是保护区和 边缘交错带间0.34、保护区和农业种植区间 0.24 , 以 及边缘交错带和农业种植区间 0.40 , 不同生境虽共 享部分蝴蝶种类, 但群落不相似。

春、夏和秋三个季节均观察到的蝴蝶有波蛱 蝶、直纹蜘蛱蝶 (Araschnia prorsoides)、波蚬蝶 (Zemeros flegyas)、菜粉蝶(Pieris rapae)、橙粉蝶 (Ixias pyrene)、达摩凤蝶、大绢斑蝶(Parantica sita)、
东方菜粉蝶、黄带褐蚬蝶(Abisara fylla)、宽边黄粉 蝶(Eurema hecabe)、亮灰蝶(Lampides boeticus)、迁 粉蝶 (Catopsilia pomona)、银纹尾蚬蝶 (Dodona eugenes)、玉玟蝶(Papilio helenus)、云粉蝶(Pontia edusa)、珍贵妩灰蝶(Udara dilecta) 和酢浆灰蝶 (Pseudozizeeria maha) 17种。春季和夏季共享蝴蝶 21 种, 群落相似性系数为 0.30 ; 春季和秋季共享蝴 蝶33种, 夏季和秋季共享31种, 群落相似性系数分 别为 0.23 和 0.22 ; 两个秋季之间共享蝴蝶 38 种, 群 落相似性系数为 0.30 ; 虽共享部分种类, 但季节间 和季节内蝴蝶群落均不相似。

总体上, 不同海拔、生境、季节间和季节内蝴 蝶群落组成有各自特点, 共享物种有限, 群落相似 性低。

\section{6 高黎贡山地区蝴蝶濒危、保护等级评估}

参照《中国物种红色名录(第三卷): 无脊椎动 物》 (汪松和解炎, 2005), 对分布于高黎贡山地区的 488 种蝴蝶进行濒危、保护等级评估, 共有67个保护 物种, 其中易危(VU)种17种、近危(NT)种50种(附录 4)。本次研究观测到的151种蝴蝶中, 易危3种, 即多 尾凤蝶、华山黛眼蝶和西峒黛眼蝶(Lethe sidonis); 近危物种 9 种, 即金裳凤蝶(Troides aeacus)、红秃尾 蚬蝶(Dodona adonira)、大斑尾蚬蝶(D. egeon)、方 裙褐蚬蝶、连斑瞑眼蝶(Ypthima sakra)、迷纹黛眼蝶、 圣母黛眼蝶 (Lethe cybele)、隐条斑粉蝶 (Delias subnubila) 和鹤顶粉蝶。其中, 多尾凤蝶、金裳凤蝶 和喙凤蝶(Teinopalpus imperialis)被列为国家二级重 点保护野生动物(见2021年2月国家林业和草原局、农 业农村部发布的《国家重点保护野生动物名录》), 高 黎贡山地区记录有喙凤蝶分布, 但本研究未观测到。

\section{讨论}

高黎贡山地区高山峡谷的独特景观、立体的气 候、微生境分化和地理隔离孕育了该地区丰富的物 种多样性(Boufford, 2014; Xing \& Ree, 2017)。本研 究首先梳理出分布于高黎贡山地区的已记录蝴蝶 461种, 加上本次调查新增的27种, 使该地区已知 蝴蝶种数达 488 种。此外, 该地区不仅蝴蝶种类丰富, 还分布着一些濒危、保护的物种。野外调查结果显 示位于1,000-2,000 $\mathrm{m}$ 的中海拔区域蝴蝶多样性最 高, 保护区内有较高的物种多样性, 秋季观测到的 
蝴蝶多样性最高。 $\alpha$ 多样性物种丰富度抽样曲线表 明: 在不同海拔、生境和季节中继续抽样, 还可以 观测到更多的蝴蝶种类, 在多样性高的中海拔区 域、保护区和秋季还可观测到更多种类; 而在低温 的高海拔地区、干扰程度高的农业种植区和多雨的 夏季继续调查到的蝴蝶种类相对有限。从时空分布 格局上看，不同海拔、生境、季节间和季节内的蝴 蝶群落, 虽共享部分种类, 但物种组成差异大, 群 落相似性低。研究结果阐明了高黎贡山地区蝴蝶的 物种多样性, 以及其群落随海拔、生境和季节变化 的模式, 可为该地区物种多样性监测和保护提供科 学依据。

蝴蝶作为生态系统中的重要类群, 对环境和气 候变化响应敏感, 作为指示物种已被广泛研究 (Lawton et al, 1998; Heikkinen et al, 2010; Herrando et al, 2016)。山地隆起假说提出在山地隆升过程所 产生的生境破碎化促进了生物多样性的分化(Xing \& Ree, 2017), 而海拔被认为是影响生物多样性的 重要因素(Gallou et al, 2017), 在山地生态系统中海 拔也是塑造蝴蝶群落组成的重要因子, 沿海拔梯度 物种丰富度呈现3种模式: 递增、递减或中海拔高峰 (Rahbek, 2004); 在东喜马拉雅地区的研究结果表 明随海拔升高, 蝴蝶多样性降低(Acharya \& Vijayan, 2015); 在新疆天山北麓东段790-2,112 m范围内, 蝴蝶多样性随海拔升高而增加(徐志峰等, 2020); 在阿尔卑斯山地区蝴蝶种群随海拔升高先增加, 到 1,900 m后急剧下降(Gallou et al, 2017)。本研究在高 黎贡山地区的中海拔地区观测到的蝴蝶多样性最 高, 支持中海拔多样性高峰模式。生境及人类活动 干扰对蝴蝶多样性的影响已被广泛关注, 通常生境 较好的保护区有较高的物种多样性, 人类干扰大的 生境不但种类减少, 群落结构也简单化(Miao et al, 2020; 房丽君等, 2020)。在农田景观格局中, 农林交 错带由于较高的环境异质性, 被认为是物种多样性 的庇护所, 有较高的生物多样性(Lourenço et al, 2019)。然而, 高黎贡山地区森林覆盖率高, 保护区 范围大，农业种植区面积小，整体上保护区物种多 样性最高, 蝴蝶类群也如此。其农林交错带主要位 于中海拔偏下段, 物种多样性表现并不高。此外, 有研究报道蝴蝶群落组成也随季节变化, 但不同分 布区呈现不同的模式(Narendra \& Varsha, 2014; 黄 敦元等, 2020); 本研究表明两个秋季调查到的蝴蝶
物种多样性均高，而且继续监测还能观察到更多物 种。这可能与高黎贡山地区中、高海拔的气候春季 回暖慢、夏季雨水多相关。此外，两个秋季调查到 的蝴蝶群落多样性也存在差异, 可能受年际间气候 波动或抽样强度影响。从蝴蝶物种的时空分布格局 来看, 不同海拔、生境和季节群落结构不相似，说 明该区域蝴蝶物种发生有自身特点，可能与植被类 型、温度耐受性等密切相关, 值得深入研究。

高黎贡山地区已知有 488 种蝴蝶，根据《中国物 种红色名录(第三卷): 无脊椎动物》(汪松和解炎, 2005)及2021年2月国家林业和草原局、农业农村部 发布的《国家重点保护野生动物名录》进行评估, 有 67 种濒危物种和 3 种二级保护野生动物, 本研究仅 观测到12种, 二级保护的喙凤蝶尚未观测到, 需加 强监测力度和持续时间。根据该区域特点，建议加 强对保护区的管理, 减少人类活动, 维持稳定的栖 息环境，有利于保护蝴蝶物种多样性; 在中海拔人 类活动地区，减少次生林和混合林间林下经济作物 的干扰，促进自然恢复或增加环境异质性，使交错 带成为保护区物种可渗透、农业区物种可回迁、庇 护物种多样性的场所。在农业种植区，倡导实施绿 色生态种植, 合理使用农药, 减少环境污染, 才能 有效保护物种多样性。

致谢: 感谢云南高黎贡山国家级自然保护区保山和 怒江管理局、保山学院及中国科学院昆明动物研究 所博物馆对本项工作的大力支持!

\section{ORCID}

易浪 (1) https://orcid.org/0000-0002-8293-4522

董亚坤 (D) https://orcid.org/0000-0002-6682-9706

苗白鸽 (D) https://orcid.org/0000-0003-0947-1602

彭艳琼 (D) https://orcid.org/ 0000-0002-7453-9119

\section{参考文献}

Acharya BK, Vijayan L (2015) Butterfly diversity along the elevation gradient of eastern Himalaya, India. Ecological Research, 30, 909-919.

Agarwala BK, Majumder J (2020) Butterfly diversity assessment in protected areas in Tripura, north eastern India. Proceedings of the Zoological Society, 73, 68-81.

Arya MK, Dayakrishna, Verma A (2020) Patterns in distribution of butterfly assemblages at different habitats of Corbett Tiger Reserve, Northern India. Tropical Ecology, 61, 180-186. 
Baselga A (2013) Separating the two components of abundance-based dissimilarity: Balanced changes in abundance vs. abundance gradients. Methods in Ecology and Evolution, 4, 552-557.

Basset Y, Barrios H, Ramirez JA, Lopez Y, Coronado J, Perez F, Arizala S, Bobadilla R, Leponce M (2017) Contrasting the distribution of butterflies and termites in plantations and tropical forests. Biodiversity and Conservation, 26, 151-176.

Boufford DE (2014) Biodiversity hotspot: China's Hengduan Mountains. Arnoldia, 72, 24-35.

Chai ZZ, Wang DX (2016) A comparison of species composition and community assemblage of secondary forests between the birch and pine-oak belts in the mid-altitude zone of the Qinling Mountains, China. PeerJ, 4, e1900.

Chao A, Chiu CH, Jost L (2014a) Unifying species diversity, phylogenetic diversity, functional diversity, and related similarity and differentiation measures through Hill numbers. Annual Review of Ecology, Evolution, and Systematics, 45, 297-324.

Chao A, Gotelli NJ, Hsieh TC, Sander EL, Ma KH, Colwell RK, Ellison AM (2014b) Rarefaction and extrapolation with Hill numbers: A framework for sampling and estimation in species diversity studies. Ecological Monographs, 84, 45-67.

Chao A, Kubota Y, Zelený D, Chiu CH, Li CF, Kusumoto B, Yasuhara M, Thorn S, Wei CL, Costello MJ, Colwell RK (2020) Quantifying sample completeness and comparing diversities among assemblages. Ecological Research, 35, 292-314.

Chen YX, Xiao ZS, Li M, Wang XW, He CX, He GP, Li HS, Shi SJ, Xiang ZF (2016) Preliminary survey for the biodiversity of mammal and bird using camera traps in the west slope of mid-section Mt. Gaoligong. Acta Theriologica Sinica, 36, 302-312. (in Chinese with English abstract) [陈 奕欣, 肖治术, 李明, 王新文, 何臣相, 何贵品, 李海曙, 施顺金, 向左甫 (2016) 利用红外相机对高黎贡山中段 西坡兽类和鸟类多样性初步调查. 兽类学报, 36, 302-312.]

Chettri N (2015) Distribution of butterflies along a trekking corridor in the Khangchendzonga Biosphere Reserve, Sikkim, Eastern Himalayas. Conservation Science, 3, 1-10.

Deng M, Liao MW, Wang CB, Liao CQ, Kang ZJ, Ma FZ, Huang GH (2020) Influence of human disturbance on butterfly diversity in the Hupingshan National Nature Reserve. Biodiversity Science, 28, 931-939. (in Chinese with English abstract) [邓敏, 廖明玮, 王晨涁, 廖承清, 康 祖杰, 马方舟, 黄国华 (2020) 人为干扰对壸瓶山国家级 自然保护区蝴蝶物种多样性的影响. 生物多样性, 28, 931-939.]

DeVries PJ, Murray D, Lande R (1997) Species diversity in vertical, horizontal, and temporal dimensions of a fruit-feeding butterfly community in an Ecuadorian rainforest. Biological Journal of the Linnaean Society, 62, 343-364.

Dong DZ, Kavanaugh DH, Li H (2002) Butterfly resources of Nujiang Canyon in Yunnan. Journal of Southwest Agricultural University, 24, 289-292. (in Chinese with English abstract) [董大志, 大卫.卡凡诺, 李恒 (2002) 云 南怒江峡谷的蝴蝶资源. 西南农业大学学报, 24, 289-292.]

Dumbacher JP, Miller J, Flannery ME, Yang XJ (2011) Avifauna of the Gaoligong Shan Mountains of western China: A hotspot of avian species diversity. Ornithological Monographs, 70, 30-63.

Fang LJ, Zhang YJ, Xing XY (2020) Butterfly community structure and diversity in Qinling National Botanical Garden, China. Biodiversity Science, 28, 965-972. (in Chinese with English abstract) [房丽君, 张宇军, 邢小宇 (2020) 秦岭国家植物园蝴蝶群落结构与多样性. 生物多 样性, 28, 965-972.]

Forister ML, McCall AC, Sanders NJ, Fordyce JA, Thorne JH, O’Brien J, Waetjen DP, Shapiro AM (2010) Compounded effects of climate change and habitat alteration shift patterns of butterfly diversity. Proceedings of the National Academy of Sciences, USA, 107, 2088-2092.

Gallou A, Baillet Y, Ficetola GF, Després L (2017) Elevational gradient and human effects on butterfly species richness in the French Alps. Ecology and Evolution, 7, 3672-3681.

Gao G, Wang B, He CX, Luo X (2017) Biodiversity of birds and mammals in alpine habitat of Mt. Gaoligong, Lushui County, Yunnan. Biodiversity Science, 25, 332-339. (in Chinese with English abstract) [高歌, 王斌, 何臣相, 罗旭 (2017) 云南泸水高黎贡山高山生境的鸟兽多样性. 生物 多样性, 25, 332-339.]

Habel JC, Segerer A, Ulrich W, Torchyk O, Weisser WW, Schmitt T (2016) Butterfly community shifts over two centuries. Conservation Biology, 30, 754-762.

Hamer KC, Hill JK, Mustaffa N, Benedick S, Sherratt TN, Chey VK, Maryati M (2005) Temporal variation in abundance and diversity of butterflies in Bornean rain forests: Opposite impacts of logging recorded in different seasons. Journal of Tropical Ecology, 21, 417-425.

He Q, Feng XH, Wang XP, Chen HB, Yang F (2019) Diversity of butterflies in Liupanshan National Nature Reserves of Ningxia. Journal of Plant Protection, 46, 1301-1309. (in Chinese with English abstract) [贺奇, 冯新华, 王新谱, 陈 红兵, 杨锋 (2019) 宁夏六盘山国家级自然保护区蝴蝶 多样性调查. 植物保护学报, 46, 1301-1309.]

Heikkinen RK, Luoto M, Leikola N, Pöyry J, Settele J, Kudrna O, Marmion M, Fronzek S, Thuiller W (2010) Assessing the vulnerability of European butterflies to climate change using multiple criteria. Biodiversity and Conservation, 19, 695-723.

Herrando S, Brotons L, Anton M, Páramo F, Villero D, Titeux 
N, Quesada J, Stefanescu C (2016) Assessing impacts of land abandonment on Mediterranean biodiversity using indicators based on bird and butterfly monitoring data. Environmental Conservation, 43, 69-78.

Hill MO (1973) Diversity and evenness: A unifying notation and its consequences. Ecology, 54, 427-432.

Hsieh TC, Ma KH, Chao A (2016) iNEXT: An R package for rarefaction and extrapolation of species diversity (Hill numbers). Methods in Ecology and Evolution, 7, 1451-1456.

Huang DY, Huang SG, Wang JH, Li HY, Dou FY, Zhang K, Zhu XL, Ma FZ (2020) Diversity of butterfly communities in the Qiyunshan National Nature Reserve. Biodiversity Science, 28, 958-964. (in Chinese with English abstract) [黄 敦元, 黄世贵, 王建皓, 李红英, 窦飞越, 张可, 朱祥龙, 马方舟 (2020) 齐云山国家级自然保护区蝴蝶群落多样 性. 生物多样性, 28, 958-964.]

Kitahara M, Sei K (2001) A comparison of the diversity and structure of butterfly communities in semi-natural and human-modified grassland habitats at the foot of Mt. Fuji, central Japan. Biodiversity and Conservation, 10, 331-351.

Kumar S, Simonson SE, Stohlgren TJ (2009) Effects of spatial heterogeneity on butterfly species richness in Rocky Mountain National Park, CO, USA. Biodiversity and Conservation, 18, 739-763.

Lawton JH, Bignell DE, Bolton B, Bloemers GF, Eggleton P, Hammond PM, Hodda M, Holt RD, Larsen TB, Mawdsley NA, Stork NE, Srivastava DS, Watt AD (1998) Biodiversity inventories, indicator taxa and effects of habitat modification in tropical forest. Nature, 391, 72-76.

Leingärtner A, Krauss J, Steffan-Dewenter I (2014) Species richness and trait composition of butterfly assemblages change along an altitudinal gradient. Oecologia, 175, 613-623.

Li H, Li R (2020) Plant Resources and Geography of the Gaoligong Mountains in Southeast Tibet. Hubei Science Press, Wuhan. (in Chinese) [李恒, 李嵘 (2020) 高黎贡山 植物资源与区系地理. 湖北科学出版社, 武汉.]

Li XY, Yang YC, He ZS, Yang GJ (2020) Diversity of butterflies community and its environmental factors in Helan Mountain Nature Reserve, Ningxia. Journal of Environmental Entomology, 42, 660-673. (in Chinese with English abstract) [李欣芸, 杨益春, 贺泽帅, 杨贵军 (2020) 宁夏贺兰山自然保护区蝴蝶群落多样性及其环境 影响因子. 环境昆虫学报, 42, 660-673.]

Liu C, Fischer G, Garcia FH, Yamane S, Liu Q, Peng YQ, Economo EP, Guénard B, Pierce NE (2020) Ants of the Hengduan Mountains: A new altitudinal survey and updated checklist for Yunnan Province highlight an understudied insect biodiversity hotspot. ZooKeys, 978, 1-171.

Liu L (2016) Investigation of species of Pieridae insects and population dynamics of dominant species in Baihualing area of Gaoligong Mountain. Journal of Baoshan University,
35(5), 11-13. (in Chinese with English abstract) [刘莉 (2016) 高黎贡山百花岭地区粉蝶科昆虫种类及其优势种 种群动态调查. 保山学院学报, 35(5), 11-13.]

Liu L, Gao HP (2014) Preliminary investigation of butterfly species in mountain natural protection high Li. Journal of Baoshan University, 33(2), 10-17. (in Chinese with English abstract) [刘莉, 高焕平 (2014) 高黎贡山百花岭地区蝴 蝶种类的初步调查. 保山学院学报, 33(2), 10-17.]

Lourenço GM, Soares GR, Santos TP, Dáttilo W, Freitas AVL, Ribeiro SP (2019) Equal but different: Natural ecotones are dissimilar to anthropic edges. PLoS ONE, 14, e0213008.

Ma FZ, Xu HG, Chen MM, Tong WJ, Wang CB, Cai L (2018) Progress in construction of China Butterfly Diversity Observation Network (China BON-Butterflies). Journal of Ecology and Rural Environment, 34, 27-36. (in Chinese with English abstract) [马方舟, 徐海根, 陈萌萌, 童文君, 王晨涁, 蔡蕾 (2018) 全国蝴蝶多样性观测网络(China BON-Butterflies)建设进展. 生态与农村环境学报, 34, 27-36.]

Miao BG, Peng YQ, Yang DR, Kubota Y, Economo EP, Liu C (2020) Climate and land-use interactively shape butterfly diversity in tropical rainforest and savanna ecosystems of southwestern China. Insect Science, https://doi.org/10.1111/ 1744-7917.12824

Myers N, Mittermeier RA, Mittermeier CG, da Fonseca GAB, Kent J (2000) Biodiversity hotspots for conservation priorities. Nature, 403, 853-858.

Narendra M, Varsha W (2014) Seasonal variation in diversity and abundance of butterfly at Sawanga Vithoba Lake area district Amravati, Maharashtra India. Journal of Biological Sciences, 14, 485-493.

Nowicki P, Settele J, Henry PY, Woyciechowski M (2008) Butterfly monitoring methods: The ideal and the real world. Israel Journal of Ecology and Evolution, 54, 69-88.

Oksanen J, Blanchet FG, Friendly M, Kindt R, Legendre P, McGlinn D, Minchin PR, O'Hara RB, Simpson GL, Solymos P, Stevens MH, Szoecs E, Wagner H (2019) Vegan: Community Ecology Package. R package version 2.5-7. https://cran.r-project.org/web/packages/vegan/index. html. (accessed on 2020-12-16)

Ou XH, Yang CQ, Song JX, Xiong J (2005) Survey and analysis of butterfly diversity in Gaoligongshan National Nature Reserve. In: Proceedings of the Sixth National Symposium on the Conservation and Sustainable Use of Biodiversity in China (ed. Ma KP), pp. 178-187. Meteorological Press, Beijing. (in Chinese) [欧晓红, 杨春 清, 宋劲忻, 熊江 (2005) 高黎贡山自然保护区蝶类多样 性的调查与分析. 见: 第六届全国生物多样性保护与持 续利用研讨会论文集(马克平主编), 178-187页. 气象出 版社, 北京.]

Pan XY, Liang D, Zeng W, Hu YM, Liang JC, Wang XW, Robinson SK, Luo X, Liu Y (2019) Climate, human disturbance and geometric constraints drive the elevational 
richness pattern of birds in a biodiversity hotspot in southwest China. Global Ecology and Conservation, 18, e00630.

Prendergast JR, Eversham BC (1995) Butterfly diversity in Southern Britain: Hotspot losses since 1930. Biological Conservation, 72, 109-114.

Rahbek C (2004) The role of spatial scale and the perception of large-scale species-richness patterns. Ecology Letters, 8, 224-239.

Samways MJ (2005) Insect Diversity Conservation. Cambridge University Press, Cambridge.

Sánchez-Fernández J, Vilchez-Vivanco JA, Navarro FB, Castro-Rodríguez J (2020) Farming system and soil management affect butterfly diversity in sloping olive groves. Insect Conservation and Diversity, 13, 456-469.

Sharma K, Acharya BK, Sharma G, Valente D, Pasimeni MR, Petrosillo I, Selvan T (2020) Land use effect on butterfly alpha and beta diversity in the Eastern Himalaya. Ecological Indicators, 110, 105605.

Thomas JA (2005) Monitoring change in the abundance and distribution of insects using butterflies and other indicator groups. Philosophical Transactions of the Royal Society B, 360, 339-357.

Wang Q, Guo ZX, Li JB, Wang KB, Wu WW, Pu ET, Ma FZ, He CX (2020) Population dynamics and diversity of butterflies in Ailaoshan and Wuliangshan national nature reserves, Yunnan Province. Biodiversity Science, 28,
921-930. (in Chinese with English abstract) [王群, 郭志祥, 李进斌, 王凯博, 吴文伟, 浦恩堂, 马方舟, 何成兴 (2020) 云南哀牢山、无量山国家级自然保护区蝴蝶种群 动态及多样性. 生物多样性, 28, 921-930.]

Wang S, Xie Y (2005) China Species Red List (Vol III): Invertebrates. Higher Education Press, Beijing. (in Chinese) [汪松, 解炎 (2005) 中国物种红色名录(第三卷): 无脊椎 动物. 高等教育出版社, 北京.]

Wu CS, Hsu YF (2017) Butterflies of China. Straits Publishing House, Fuzhou. (in Chinese) [武春生, 徐垤峰 (2017) 中 国蝴蝶图鉴. 海峡书局, 福州.]

Xing YW, Ree RH (2017) Uplift-driven diversification in the Hengduan Mountains, a temperate biodiversity hotspot. Proceedings of the National Academy of Sciences, USA, 114, E3444-E3451.

Xu ZF, Zhong W, Zhang DK, Hu HY (2020) Diversity of butterfly communities in Jimusaer County, Xinjiang. Biodiversity Science, 28, 993-1002. (in Chinese with English abstract) [徐志峰, 钟问, 张东康, 胡红英 (2020) 新疆吉木萨尔县蝴蝶群落多样性。生物多样性, 28, 993-1002.]

Yang PZ, Zi LH, Liu SR (2016) The Moths of Gaoligong Mountains. Science Press, Beijing. (in Chinese) [杨平之, 资丽华, 刘淑蓉 (2016) 高黎贡山蛾类图鉴. 科学出版 社, 北京.]

(责任编委：白明 责任编辑：问文杰)

\section{附录 Supplementary Material}

附录1 云南高黎贡山地区蝴蝶物种名录

Appendix 1 Species list of recorded butterflies in Gaoligong region of Yunnan https://www.biodiversity-science.net/fileup/PDF/2020486-1.pdf

附录2 云南高黎贡山地区127条蝴蝶调查样线分布图

Appendix 2 Distribution of 127 transects for butterfly survey in Gaoligong region of Yunnan https://www.biodiversity-science.net/fileup/PDF/2020486-2.pdf

附录3 云南高黎贡山地区观测到的蝴蝶物种分布格局

Appendix 3 Distribution pattern of investigated butterflies in Gaoligong region of Yunnan https://www.biodiversity-science.net/fileup/PDF/2020486-3.pdf

附录4 云南高黎贡山地区濒危、保护蝴蝶物种名录

Appendix 4 List of endangered and protected butterfly species in Gaoligong region of Yunnan https://www.biodiversity-science.net/fileup/PDF/2020486-4.pdf 
易浪, 董亚坤, 苗白鸽, 彭艳琼 (2021) 云南高黎贡山地区蝴蝶群落多样性. 生物多样性, 29, 950-959. https://www.biodiversity-science.net/CN/10.17520/biods.2020486

附录1 云南高黎贡山地区蝴蝶物种名录

Appendix 1 Species list of recorded butterflies in Gaoligong region of Yunnan

\begin{tabular}{|c|c|c|c|c|}
\hline \multirow{3}{*}{$\begin{array}{l}\text { 科 } \\
\text { Family }\end{array}$} & \multirow{3}{*}{$\begin{array}{l}\text { 种类 } \\
\text { Species }\end{array}$} & \multicolumn{3}{|c|}{ 来源 Resources } \\
\hline & & 文献 & 馆藏标本* & 调查 \\
\hline & & Literatures & Specimens* & Investigation \\
\hline 粉蝶科 & 完善绢粉蝶 Aporia agathon & $2 、 3$ & & \\
\hline \multirow[t]{37}{*}{ Pieridae } & 普通绢粉蝶 Aporia genestieri & 1 & & \\
\hline & 锯纹绢粉蝶 Aporia goutellei & 1 & & \\
\hline & 利箭绢粉蝶 Aporia harrietae & 1 & $\mathrm{~b}$ & \\
\hline & 小檗绢粉蝶 Aporia hippia & 3 & & \\
\hline & 大翅绢粉蝶 Aporia largeteaui & 3 & & \\
\hline & 三黄绢粉蝶 Aporia larraldei & $1 、 3$ & & \\
\hline & 箭纹绢粉蝶 Aporia procris & 3 & & \\
\hline & 兰姬尖粉蝶 Appias lalage & 3 & & \\
\hline & 兰西尖粉蝶 Appias lalassis & 1 & & \\
\hline & 灵奇尖粉蝶 Appias lyncida & & a & \\
\hline & 迁粉蝶 Catopsilia pomona & $1,2 、 3$ & $a b$ & $\sqrt{ }$ \\
\hline & 青园粉蝶 Cepora nadina & 3 & & $\sqrt{ }$ \\
\hline & 黑脉园粉蝶 Cepora nerissa & 5,6 & a & $\sqrt{ }$ \\
\hline & 橙黄豆粉蝶 Colias fieldii & $1 、 2$ & $\mathrm{~b}$ & $\sqrt{ }$ \\
\hline & 东亚豆粉蝶 Colias poliographus & & $\mathrm{a}$ & \\
\hline & 红腋斑粉蝶 Delias acalis & 2 & & $\sqrt{ }$ \\
\hline & 奥古斑粉蝶 Delias agostina & 3 & & \\
\hline & 艳妇斑粉蝶 Delias belladonna & $1,2 、 3$ & & $\sqrt{ }$ \\
\hline & 优越斑粉蝶 Delias hyparete & $3,5,6$ & a & $\sqrt{ }$ \\
\hline & 侧条斑粉蝶 Delias lativitta & 1 & & \\
\hline & 内黄斑粉蝶 Delias partrua & 1 & $\mathrm{a}$ & \\
\hline & 报喜斑粉蝶 Delias pasithoe & $3,5,6$ & a & $\sqrt{ }$ \\
\hline & 酒青斑粉蝶 Delias sanaca & 1 & & \\
\hline & 隐条斑粉蝶 Delias subnubila & & & $\sqrt{ }$ \\
\hline & 黄裙斑粉蝶 Delias wilemani & 3 & & \\
\hline & 黑角方粉蝶 Dercas lycorias & 1 & a & $\sqrt{ }$ \\
\hline & 橙翅方粉蝶 Dercas nina & 3 & & \\
\hline & 檀方粉蝶 Dercas verhuelli & 3 & a & \\
\hline & 安迪黄粉蝶 Eurema andersoni & & & $\sqrt{ }$ \\
\hline & 檗黄粉蝶 Eurema blanda & $2 、 5$ & & $\sqrt{ }$ \\
\hline & 无标黄粉蝶 Eurema brigitta & 3 & $\mathrm{ab}$ & $\sqrt{ }$ \\
\hline & 宽边黄粉蝶 Eurema hecabe & $2 、 3,5$ & $a b$ & $\sqrt{ }$ \\
\hline & 尖角黄粉蝶 Eurema laeta & $1 、 2$ & $a b$ & $\sqrt{ }$ \\
\hline & 北黄粉蝶 Eurema mandarina & & & $\sqrt{ }$ \\
\hline & 圆翅钩粉蝶 Gonepteryx amintha & 3 & a & \\
\hline & 淡色钩粉蝶 Gonepteryx aspasia & 3 & & \\
\hline & 鹤顶粉蝶 Hebomoia glaucippe & $2 、 3$ & $\mathrm{a}$ & $\sqrt{ }$ \\
\hline
\end{tabular}


易浪, 董亚坤, 苗白鸽, 彭艳琼 (2021) 云南高黎贡山地区蝴蝶群落多样性. 生物多样性, 29, 950-959. https://www.biodiversity-science.net/CN/10.17520/biods.2020486

\begin{tabular}{|c|c|c|c|c|}
\hline \multirow{3}{*}{$\begin{array}{l}\text { 科 } \\
\text { Family }\end{array}$} & \multirow{3}{*}{$\begin{array}{l}\text { 种类 } \\
\text { Species }\end{array}$} & \multicolumn{3}{|c|}{ 来源 Resources } \\
\hline & & 文献 & 馆藏标本* & 调查 \\
\hline & & Literatures & Specimens* & Investigation \\
\hline & 橙粉蝶 Ixias pyrene & $3 、 5,6$ & $\mathrm{ab}$ & $\sqrt{ }$ \\
\hline & 妹粉蝶 Mesapia peloria & 3 & & \\
\hline & 青粉蝶 Pareronia valeria & 5 & & \\
\hline & 欧洲粉蝶 Pieris brassicae & & $\mathrm{a}$ & $\sqrt{ }$ \\
\hline & 东方菜粉蝶 Pieris canidia & 3 & $\mathrm{ab}$ & $\sqrt{ }$ \\
\hline & 斑缘菜粉蝶 Pieris deota & 5,6 & & \\
\hline & 杜贝粉蝶 Pieris dubernardi & 5,6 & & \\
\hline & 黑纹粉蝶 Pieris melete & 2 & a & $\sqrt{ }$ \\
\hline & 暗脉菜粉蝶 Pieris napi & & $\mathrm{b}$ & \\
\hline & 菜粉蝶 Pieris rapae & $2 、 5,6$ & $\mathrm{ab}$ & $\sqrt{ }$ \\
\hline & 斯托粉蝶 Pieris stotzneri & 1 & & \\
\hline & 云粉蝶 Pontia edusa & $2,3,5,6$ & a & $\sqrt{ }$ \\
\hline & 锯粉蝶 Prioneris thestylis & $2 、 3 、 1$ & & \\
\hline & 飞龙粉蝶 Talbotia naganum & 5,6 & & \\
\hline 凤蝶科 & 多尾凤蝶 Bhutanitis lidderdalii & 1 & a & $\sqrt{ }$ \\
\hline \multirow[t]{25}{*}{ Papilionidae } & 瘪凤蝶 Byasa alcinous & 3 & & \\
\hline & 达摩鹰凤蝶 Byasa daemonius & 3 & & \\
\hline & 白斑鹿风蝶 Byasa dasarada & $1 、 2$ & $\mathrm{~b}$ & \\
\hline & 云南謝凤蝶 Byasa hedistus & 1 & & \\
\hline & 纨裤鹿凤蝶 Byasa latreillei & $1 、 3 、 4$ & $\mathrm{a}$ & \\
\hline & 粗线㯍凤蝶 Byasa nevilli & & $\mathrm{a}$ & \\
\hline & 突缘瘪凤蝶 Byasa plutonius & 1 & & \\
\hline & 多姿膺风蝶 Byasa polyeuctes & $1 、 2$ & a & $\sqrt{ }$ \\
\hline & 斑凤蝶 Chilasa clytia & & $\mathrm{b}$ & \\
\hline & 宽带青凤蝶 Graphium cloanthus & 1 & $\mathrm{a}$ & \\
\hline & 青凤蝶 Graphium sarpedon & 3 & $\mathrm{ab}$ & $\sqrt{ }$ \\
\hline & 燕凤蝶 Lamproptera curius & 3 & $\mathrm{~b}$ & \\
\hline & 褐钩凤蝶 Meandrusa sciron & 4 & & \\
\hline & 褐斑凤蝶 Papilio agestor & 1 & & \\
\hline & 红基美凤蝶 Papilio alcmenor & 3 & & \\
\hline & 窄斑翠凤蝶 Papilio arcturus & 1 & a & \\
\hline & 碧凤蝶 Papilio bianor & $1 、 3$ & a & $\sqrt{ }$ \\
\hline & 牛郎凤蝶 Papilio bootes & 1 & & \\
\hline & 达摩凤蝶 Papilio demoleus & 3 & $\mathrm{ab}$ & $\sqrt{ }$ \\
\hline & 玉玟凤蝶 Papilio helenus & $2 、 3$ & $\mathrm{ab}$ & $\sqrt{ }$ \\
\hline & 克里翠凤蝶 Papilio krishna & 1 & & \\
\hline & 金凤蝶 Papilio machaon & $1,2 、 3$ & $\mathrm{a}$ & \\
\hline & 宽带凤蝶 Papilio nephelus & 3 & & \\
\hline & 巴黎翠凤蝶 Papilio paris & $2 、 3$ & $a b$ & $\sqrt{ }$ \\
\hline & 玉带凤蝶 Papilio polytes & $1 、 3$ & $\mathrm{a}$ & $\sqrt{ }$ \\
\hline
\end{tabular}


易浪, 董亚坤, 苗白鸽, 彭艳琼 (2021) 云南高黎贡山地区蝴蝶群落多样性. 生物多样性, 29, 950-959. https://www.biodiversity-science.net/CN/10.17520/biods.2020486

\begin{tabular}{|c|c|c|c|c|}
\hline \multirow{3}{*}{$\begin{array}{l}\text { 科 } \\
\text { Family }\end{array}$} & \multirow{3}{*}{$\begin{array}{l}\text { 种类 } \\
\text { Species }\end{array}$} & \multicolumn{3}{|c|}{ 来源 Resources } \\
\hline & & 文献 & 馆藏标本* & 调查 \\
\hline & & Literatures & Specimens* & Investigation \\
\hline & 蓝凤蝶 Papilio protenor & $2,3,4$ & $\mathrm{ab}$ & \\
\hline & 柑橘凤蝶 Papilio xuthus & $2 、 4$ & a & $\sqrt{ }$ \\
\hline & 斜纹绿风蝶 Pathysa agetes & 3 & & \\
\hline & 绿凤蝶 Pathysa antiphates & 3 & & \\
\hline & 红绶绿风蝶 Pathysa nomius & 7 & & \\
\hline & 华夏剑凤蝶 Pazala mandarinus & $1 、 3$ & & \\
\hline & 圆翅剑凤蝶 Pazala parus & 1 & & \\
\hline & 乌克兰剑凤蝶 Pazala tamerlana & 3 & & \\
\hline & 喙凤蝶 Teinopalpus imperialis & 1 & & \\
\hline & 金裳凤蝶 Troides aeacus & 1 & $a b$ & $\sqrt{ }$ \\
\hline & 元首绢蝶 Parnassius cephalus & 3 & & \\
\hline & 西猴绢蝶 Parnassius simo & 3 & & \\
\hline 灰蝶科 & 钮灰蝶 Acytolepis puspa & & & $\sqrt{ }$ \\
\hline \multirow[t]{27}{*}{ Lycaenidae } & 百娆灰蝶 Arhopala bazala & & & $\sqrt{ }$ \\
\hline & 驳灰蝶 Bothrinia nebulosa & 7 & & \\
\hline & 散纹拓灰蝶 Caleta elna & & & $\sqrt{ }$ \\
\hline & 豹灰蝶 Castalius rosimon & 2 & & $\sqrt{ }$ \\
\hline & 咖灰蝶 Catochrysops strabo & 2 & & $\sqrt{ }$ \\
\hline & 熏衣琉璃灰蝶 Celastrina argiola & 2 & & $\sqrt{ }$ \\
\hline & 华西琉璃灰蝶 Celastrina hersilia & & $\mathrm{b}$ & \\
\hline & 薰琉璃灰蝶 Celastrina lavendularis & & $\mathrm{b}$ & \\
\hline & 大紫琉璃灰蝶 Celastrina oreas & $1 、 2$ & & $\sqrt{ }$ \\
\hline & 皿玉灰蝶 Celatoxia marginata & 1 & & $\sqrt{ }$ \\
\hline & 紫灰蝶 Chilades lajus & & & $\sqrt{ }$ \\
\hline & 曲纹紫灰蝶 Chilades pandava & & & $\sqrt{ }$ \\
\hline & 普紫灰蝶 Chilades putli & & & $\sqrt{ }$ \\
\hline & 吉蒲灰蝶 Chliaria kina & 1、 4 & & \\
\hline & 加布雷金灰蝶 Chrysozephyrus kabrua & & $\mathrm{b}$ & \\
\hline & 喀巴利金灰蝶 Chrysozephyrus kirbariensis & 1 & & \\
\hline & 帕金灰蝶 Chrysozephyrus paona & 1 & & \\
\hline & 闪光金灰蝶 Chrysozephyrus scintillans & 5 & & \\
\hline & 云南金灰蝶 Chrysozephyrus yunnanensis & 1 & & \\
\hline & 尖翅银灰蝶 Curetis acuta & 3,5 & $\mathrm{ab}$ & $\sqrt{ }$ \\
\hline & 深山玳灰蝶 Deudorix sylvana & 1 & & \\
\hline & 江崎灰蝶 Esakiozephyrus icana & 1 & & \\
\hline & 棕灰蝶 Euchrysops cnejus & 2 & & \\
\hline & 蓝灰蝶 Everes argiades & & $\mathrm{b}$ & $\sqrt{ }$ \\
\hline & 长尾蓝灰蝶 Everes lacturnus & 5 & & \\
\hline & 艳灰蝶 Favonius orientalis & 1 & & \\
\hline & 美男彩灰蝶 Heliophorus androcles & 1 & & $\sqrt{ }$ \\
\hline
\end{tabular}


易浪, 董亚坤, 苗白鸽, 彭艳琼 (2021) 云南高黎贡山地区蝴蝶群落多样性. 生物多样性, 29, 950-959. https://www.biodiversity-science.net/CN/10.17520/biods.2020486

\begin{tabular}{|c|c|c|c|c|}
\hline \multirow{3}{*}{$\begin{array}{l}\text { 科 } \\
\text { Family }\end{array}$} & \multirow{3}{*}{$\begin{array}{l}\text { 种类 } \\
\text { Species }\end{array}$} & \multicolumn{3}{|c|}{ 来源 Resources } \\
\hline & & 文献 & 馆藏标本* & 调查 \\
\hline & & Literatures & Specimens* & Investigation \\
\hline & 古铜彩灰蝶 Heliophorus brahma & 3 & $\mathrm{~b}$ & $\sqrt{ }$ \\
\hline & 依彩灰蝶 Heliophorus eventa & 1 & & $\sqrt{ }$ \\
\hline & 浓紫彩灰蝶 Heliophorus ila & $2 、 3$ & $\mathrm{~b}$ & $\sqrt{ }$ \\
\hline & 摩来彩灰蝶 Heliophorus moorei & 7 & $\mathrm{~b}$ & \\
\hline & 斜斑彩灰蝶 Heliophorus phoenicoparyphus & 2 & & \\
\hline & 美丽彩灰蝶 Heliophorus pulcher & 7 & & \\
\hline & 莎菲彩灰蝶 Heliophorus saphir & 3 & & \\
\hline & 塔彩灰蝶 Heliophorus tamu & 1 & & \\
\hline & 丽罕菜灰蝶 Helleia li & 3 & & \\
\hline & 磐灰蝶 Iwaseozephyrus mandara & 1 & & \\
\hline & 素雅灰蝶 Jamides alecto & & & $\sqrt{ }$ \\
\hline & 雅灰蝶 Jamides bochus & 2 & & $\sqrt{ }$ \\
\hline & 亮灰蝶 Lampides boeticus & 2 & $\mathrm{~b}$ & $\sqrt{ }$ \\
\hline & 细灰蝶 Leptotes plinius & & & $\sqrt{ }$ \\
\hline & 鹿灰蝶 Loxura atymnus & $2 、 3$ & & $\sqrt{ }$ \\
\hline & 红灰蝶 Lycaena phlaeas & 7 & & \\
\hline & 穆灰蝶 Monodontides musina & 1 & & \\
\hline & 黑灰蝶 Niphanda fusca & 7 & & \\
\hline & 锯灰蝶 Orthomiella pontis & 2 & & $\sqrt{ }$ \\
\hline & 白灰蝶 Phengaris atroguttata & 1 & & \\
\hline & 多眼灰蝶 Polyommatus eros & 7 & & \\
\hline & 疑波灰蝶 Prosotas dubiosa & & & $\sqrt{ }$ \\
\hline & 娜拉波灰蝶 Prosotas nora & & & $\sqrt{ }$ \\
\hline & 酢浆灰蝶 Pseudozizeeria maha & 2 & $\mathrm{~b}$ & $\sqrt{ }$ \\
\hline & 红燕灰蝶 Rapala iarbus & 2 & & \\
\hline & 东亚燕灰蝶 Rapala micans & 1 & & \\
\hline & 点染燕灰蝶 Rapala suffusa & 3 & & \\
\hline & 川滇酒灰蝶 Satyrium fixseni & 1 & & \\
\hline & 山灰蝶 Shijimia moorei & 7 & & \\
\hline & 生灰蝶 Sinthusa chandrana & & & $\sqrt{ }$ \\
\hline & 白生灰蝶 Sinthusa virgo & 1 & & \\
\hline & 银线灰蝶 Spindasis lohita & 7 & $\mathrm{~b}$ & $\sqrt{ }$ \\
\hline & 豆粒银线灰蝶 Spindasis syama & $2 、 3 、 4$ & $\mathrm{~b}$ & $\sqrt{ }$ \\
\hline & 白日双尾灰蝶 Tajuria diaeus & 1 & & \\
\hline & 凯丽藤灰蝶 Tarucus callinara & & & $\sqrt{ }$ \\
\hline & 宽带玄灰蝶 Tongeia amplifascia & 1 & & \\
\hline & 波太玄灰蝶 Tongeia potanini & 1 & & \\
\hline & 珍贵妩灰蝶 Udara dilecta & 3 & $\mathrm{~b}$ & $\sqrt{ }$ \\
\hline & 吉灰蝶 Zizeeria karsandra & & & $\sqrt{ }$ \\
\hline & 毛眼灰蝶 Zizina otis & 2 & $\mathrm{~b}$ & $\sqrt{ }$ \\
\hline
\end{tabular}


易浪, 董亚坤, 苗白鸽, 彭艳琼 (2021) 云南高黎贡山地区蝴蝶群落多样性. 生物多样性, 29, 950-959. https://www.biodiversity-science.net/CN/10.17520/biods.2020486

\begin{tabular}{|c|c|c|c|c|}
\hline \multirow{3}{*}{$\begin{array}{l}\text { 科 } \\
\text { Family }\end{array}$} & \multirow{3}{*}{$\begin{array}{l}\text { 种类 } \\
\text { Species }\end{array}$} & \multicolumn{3}{|c|}{ 来源 Resources } \\
\hline & & 文献 & 馆藏标本* & 调查 \\
\hline & & Literatures & Specimens* & Investigation \\
\hline & 长腹灰蝶 Zizula hylax & & & $\sqrt{ }$ \\
\hline & 曲带褐蚬蝶 Abisara abnormis & 3 & & \\
\hline & 方裙褐蚬蝶 Abisara freda & 3 & & $\sqrt{ }$ \\
\hline & 黄带褐蚬蝶 Abisara fylla & $2 、 3$ & $\mathrm{a}$ & $\sqrt{ }$ \\
\hline & 白带褐蚬蝶 Abisara fylloides & 3 & & $\sqrt{ }$ \\
\hline & 长尾褐蚬蝶 Abisara neophron & 3、 4 & $\mathrm{~b}$ & \\
\hline & 红秃尾蚬蝶 Dodona adonira & & $\mathrm{b}$ & $\sqrt{ }$ \\
\hline & 黑燕尾蚬蝶 Dodona deodata & 3 & & $\sqrt{ }$ \\
\hline & 秃尾蚬蝶 Dodona dipoea & 1、 2 & $\mathrm{~b}$ & $\sqrt{ }$ \\
\hline & 大斑尾蚬蝶 Dodona egeon & 1,3 & $\mathrm{~b}$ & $\sqrt{ }$ \\
\hline & 银纹尾蚬蝶 Dodona eugenes & 3 & $\mathrm{~b}$ & $\sqrt{ }$ \\
\hline & 白燕尾蚬蝶 Dodona henrici & 3 & $\mathrm{~b}$ & \\
\hline & 高黎贡尾蚬蝶 Dodona kaolinkon & 1 & & \\
\hline & 斜带缺尾蚬蝶 Dodona ouida & 2 & & $\sqrt{ }$ \\
\hline & 喇嘛小蚬蝶 Polycaena lama & 3 & & \\
\hline & 波蚬蝶 Zemeros flegyas & $2 、 3 、 5$ & $a b$ & $\sqrt{ }$ \\
\hline 蛱蝶科 & 邚蛱蝶 Abrota ganga & 1 & & \\
\hline \multirow[t]{23}{*}{ Nymphalidae } & 中华荨麻蛱蝶 Aglais chinensis & 1 & a & \\
\hline & 菖麻蛱蝶 Aglais urticae & $2 、 3$ & & \\
\hline & 印度紫蛱蝶 Apatura ambica & 3 & & \\
\hline & 柳紫闪蛱蝶 Apatura ilia & & $\mathrm{b}$ & \\
\hline & 紫闪蛱蝶 Apatura iris & 3 & & \\
\hline & 大卫蜘蛱蝶 Araschnia davidis & 1 & & \\
\hline & 曲纹蜘蛱蝶 Araschnia doris & 7 & & \\
\hline & 直纹蜘蛱蝶 Araschnia prorsoides & $3 、 5$ & $a b$ & $\sqrt{ }$ \\
\hline & 绿豹蛱蝶 Argynnis paphia & 5 & & \\
\hline & 斐豹蛱蝶 Argyreus hyperbius & 7 & $a b$ & $\sqrt{ }$ \\
\hline & 老豹蛱蝶 Argyronome laodice & 3 & $\mathrm{~b}$ & \\
\hline & 红老豹蛱蝶 Argyronome ruslana & & $\mathrm{b}$ & \\
\hline & 波蛱蝶 Ariadne ariadne & 3,5 & a & $\sqrt{ }$ \\
\hline & 细纹波蛱蝶 Ariadne merione & 2 & a & \\
\hline & 双色带蛱蝶 Athyma cama & $2 、 3 、 5$ & & \\
\hline & 玉杵带蛱蝶 Athyma jina & & $\mathrm{b}$ & $\sqrt{ }$ \\
\hline & 相思带蛱蝶 Athyma nefte & & & $\sqrt{ }$ \\
\hline & 虬眉带蛱蝶 Athyma opalina & 1 & & $\sqrt{ }$ \\
\hline & 东方带蛱蝶 Athyma orientalis & & $\mathrm{a}$ & \\
\hline & 玄珠带蛱蝶 Athyma perius & 3 & & $\sqrt{ }$ \\
\hline & 六点带蛱蝶 Athyma punctata & 1 & & \\
\hline & 奥蛱蝶 Auzakia danava & $1 、 2$ & & \\
\hline & 单银斑小豹蛱蝶 Boloria euphrosyne & 3 & & \\
\hline
\end{tabular}


易浪, 董亚坤, 苗白鸽, 彭艳琼 (2021) 云南高黎贡山地区蝴蝶群落多样性. 生物多样性, 29, 950-959. https://www.biodiversity-science.net/CN/10.17520/biods.2020486

\begin{tabular}{|c|c|c|c|c|}
\hline \multirow{3}{*}{$\begin{array}{l}\text { 科 } \\
\text { Family }\end{array}$} & \multirow{3}{*}{$\begin{array}{l}\text { 种类 } \\
\text { Species }\end{array}$} & \multicolumn{3}{|c|}{ 来源 Resources } \\
\hline & & 文献 & 馆藏标本* & 调查 \\
\hline & & Literatures & Specimens* & Investigation \\
\hline & 小豹蛱蝶 Brenthis daphne & $3 、 5$ & & \\
\hline & 绢蛱蝶 Calinaga buddha & 1 & $\mathrm{~b}$ & \\
\hline & 大卫绢蛱蝶 Calinaga davidis & 1 & $\mathrm{a}$ & \\
\hline & 红锯蛱蝶 Cethosia biblis & $2 、 5$ & $\mathrm{ab}$ & $\sqrt{ }$ \\
\hline & 白带锯蛱蝶 Cethosia cyane & $2 、 3$ & a & \\
\hline & 姹蛱蝶 Chalinga elwesi & $1 、 3$ & & \\
\hline & 黄绢坎蛱蝶 Chersonesia risa & & & $\sqrt{ }$ \\
\hline & 银豹蛱蝶 Childrena children & $2 、 3 、 5$ & $a b$ & $\sqrt{ }$ \\
\hline & 幸运辘蛱蝶 Cirrochroa tyche & 5 & $\mathrm{~b}$ & $\sqrt{ }$ \\
\hline & 网丝蛱蝶 Cyrestis thyodamas & 3 & a & \\
\hline & 青豹蛱蝶 Damora sagana & 3,5 & & $\sqrt{ }$ \\
\hline & 电蛱蝶 Dichorragia nesimachus & & $\mathrm{a}$ & \\
\hline & 明窗蛱蝶 Dilipa fenestra & 5 & & \\
\hline & 窗蛱蝶 Dilipa morgiana & & $\mathrm{a}$ & \\
\hline & 芒蛱蝶 Euripus nyctelius & 3 & & \\
\hline & 矛翠蛱蝶 Euthalia aconthea & $2 、 3$ & & \\
\hline & V纹翠蛱蝶 Euthalia alpheda & 3 & & \\
\hline & 鹰翠蛱蝶 Euthalia anosia & 3 & & \\
\hline & 渡带翠蛱蝶 Euthalia duda & 7 & & \\
\hline & 珐琅翠蛱蝶 Euthalia franciae & & $\mathrm{b}$ & \\
\hline & 窄带翠蛱蝶 Euthalia insulae & 1 & & \\
\hline & 嘉翠蛱蝶 Euthalia kardama & 3 & & \\
\hline & 白裙翠蛱蝶 Euthalia lepidea & 3 & & \\
\hline & 红斑翠蛱蝶 Euthalia lubentina & 3 & & \\
\hline & 黄铜翠蛱蝶 Euthalia nara & $1 、 4$ & $\mathrm{a}$ & \\
\hline & 链斑翠蛱蝶 Euthalia sahadeva & 5 & & \\
\hline & 小渡带翠蛱蝶 Euthalia sakota & & $\mathrm{a}$ & \\
\hline & 西藏翠蛱蝶 Euthalia thibetana & 3 & & \\
\hline & 灿福蛱蝶 Fabriciana adippe & 3 & & \\
\hline & 蟾福蛱蝶 Fabriciana nerippe & 3 & & \\
\hline & 爻蛱蝶 Herona marathus & 3 & & \\
\hline & 茬藜纹脉蛱蝶 Hestina nama & $2 、 3$ & $\mathrm{ab}$ & $\sqrt{ }$ \\
\hline & 拟斑脉蛱蝶 Hestina persimilis & 3 & & \\
\hline & 幻紫斑蛱蝶 Hypolimnas bolina & $2 、 3$ & a & $\sqrt{ }$ \\
\hline & 金斑蛱蝶 Hypolimnas missipus & $3 、 5$ & & \\
\hline & 美眼蛱蝶 Junonia almana & 7 & $\mathrm{~b}$ & $\sqrt{ }$ \\
\hline & 黄裳眼蛱蝶 Junonia hierta & 3 & $\mathrm{~b}$ & $\sqrt{ }$ \\
\hline & 钩翅眼蛱蝶 Junonia iphita & 7 & $\mathrm{~b}$ & $\sqrt{ }$ \\
\hline & 蛇眼蛱蝶 Junonia lemonias & 3 & & $\sqrt{ }$ \\
\hline & 翠蓝眼蛱蝶 Junonia orithya & $2 、 3 、 5$ & $a b$ & $\sqrt{ }$ \\
\hline
\end{tabular}


易浪, 董亚坤, 苗白鸽, 彭艳琼 (2021) 云南高黎贡山地区蝴蝶群落多样性. 生物多样性, 29, 950-959. https://www.biodiversity-science.net/CN/10.17520/biods.2020486

\begin{tabular}{|c|c|c|c|c|}
\hline \multirow{3}{*}{$\begin{array}{l}\text { 科 } \\
\text { Family }\end{array}$} & \multirow{3}{*}{$\begin{array}{l}\text { 种类 } \\
\text { Species }\end{array}$} & \multicolumn{3}{|c|}{ 来源 Resources } \\
\hline & & 文献 & 馆藏标本* & 调查 \\
\hline & & Literatures & Specimens* & Investigation \\
\hline & 琉璃蛱蝶 Kaniska canace & $1 、 2 、 3$ & & $\sqrt{ }$ \\
\hline & 黑角律蛱蝶 Lexias dirtea & 3 & & \\
\hline & 戟眉线蛱蝶 Limenitis homeyeri & 1 & $\mathrm{~b}$ & \\
\hline & 拟戟眉线蛱蝶 Limenitis misuji & 1 & & \\
\hline & 残锷线蛱蝶 Limenitis sulpitia & & $a b$ & \\
\hline & 缕蛱蝶 Litinga cottini & $1 、 3$ & & \\
\hline & 拟缕蛱蝶 Litinga mimica & 1 & & \\
\hline & 阿尔网蛱蝶 Melitaea arcesia & 3 & & \\
\hline & 黑网蛱蝶 Melitaea jezabel & 3 & & \\
\hline & 圆翅网蛱蝶 Melitaea yuenty & $2 、 3$ & $a b$ & \\
\hline & 环带迷蛱蝶 Mimathyma ambica & 7 & & \\
\hline & 迷蛱蝶 Mimathyma chevana & 1 & & \\
\hline & 穆蛱蝶 Moduza procris & 3 & & \\
\hline & 重环蛱蝶 Neptis alwina & 7 & & \\
\hline & 阿环蛱蝶 Neptis ananta & 1 & & \\
\hline & 羚环蛱蝶 Neptis antilope & 1 & & \\
\hline & 蛛环蛱蝶 Neptis arachne & 1 & & \\
\hline & 矛环蛱蝶 Neptis armandia & 1 & & \\
\hline & 折环蛱蝶 Neptis beroe & 7 & & \\
\hline & 德环蛱蝶 Neptis dejeani & 1,3 & $\mathrm{~b}$ & \\
\hline & 五段环蛱蝶 Neptis divisa & 1 & & \\
\hline & 中环蛱蝶 Neptis hylas & 2 & $\mathrm{~b}$ & $\sqrt{ }$ \\
\hline & 宽环蛱蝶 Neptis mahendra & $1 、 3$ & & \\
\hline & 玛环蛱蝶 Neptis manasa & 1 & & \\
\hline & 弥环蛱蝶 Neptis miah & 3,5 & $\mathrm{~b}$ & \\
\hline & 基环蛱蝶 Neptis nashona & 3 & & \\
\hline & 娜环蛱蝶 Neptis nata & 3 & & \\
\hline & 森环蛱蝶 Neptis nemorum & 3 & & \\
\hline & 链环蛱蝶 Neptis pryeri & & $\mathrm{b}$ & \\
\hline & 断环蛱蝶 Neptis sankara & 1 & a & \\
\hline & 小环蛱蝶 Neptis sappho & 3 & $\mathrm{~b}$ & $\sqrt{ }$ \\
\hline & 娑环蛱蝶 Neptis soma & & $\mathrm{b}$ & \\
\hline & 黄环蛱蝶 Neptis themis & 1 & & \\
\hline & 泰环蛱蝶 Neptis thestias & 1 & & \\
\hline & 云南环蛱蝶 Neptis yunnana & 1 & & \\
\hline & 金环蛱蝶 Neptis zaida & 1 & & \\
\hline & 金蟠蛱蝶 Pantoporia hordoni & 3 & & \\
\hline & Y纹俳蛱蝶 Parasarpa dudu & & $\mathrm{b}$ & \\
\hline & 彩衣俳蛱蝶 parasarpa hourberti & $1 、 3 、 4$ & & \\
\hline & 西藏俳蛱蝶 Parasarpa zayla & 1 & & $\sqrt{ }$ \\
\hline
\end{tabular}


易浪, 董亚坤, 苗白鸽, 彭艳琼 (2021) 云南高黎贡山地区蝴蝶群落多样性. 生物多样性, 29, 950-959. https://www.biodiversity-science.net/CN/10.17520/biods.2020486

\begin{tabular}{|c|c|c|c|c|}
\hline \multirow{3}{*}{$\begin{array}{l}\text { 科 } \\
\text { Family }\end{array}$} & \multirow{3}{*}{$\begin{array}{l}\text { 种类 } \\
\text { Species }\end{array}$} & \multicolumn{3}{|c|}{ 来源 Resources } \\
\hline & & 文献 & 馆藏标本* & 调查 \\
\hline & & Literatures & Specimens* & Investigation \\
\hline & 丽蛱蝶 Parthenos sylvia & 7 & & \\
\hline & 柱菲蛱蝶 Phaedyma columella & 7 & & \\
\hline & 珐蛱蝶 Phalanta phalantha & $2 、 3$ & $a b$ & $\sqrt{ }$ \\
\hline & 银钩角蛱蝶 Polygonia c-album & 3 & & \\
\hline & 黄钩蛱蝶 Polygonia c-aureum & 3 & $\mathrm{~b}$ & \\
\hline & 凤尾蛱蝶 Polyura arja & & & $\sqrt{ }$ \\
\hline & 窄斑凤尾蛱蝶 Polyura athamas & 3 & $\mathrm{a}$ & \\
\hline & 针尾蛱蝶 Polyura dolon & 3 & a & \\
\hline & 大二尾蛱蝶 Polyura eudamippus & 3 & & \\
\hline & 二尾蛱蝶 Polyura narcaea & 3 & a & \\
\hline & 秀蛱蝶 Pseudergolis wedah & $1,2 、 3 、 5$ & $a b$ & $\sqrt{ }$ \\
\hline & 罗蛱蝶 Rohana parisatis & 3 & & \\
\hline & 大紫蛱蝶 Sasakia charonda & 1 & & \\
\hline & 帅蛱蝶 Sephisa chandra & 3 & & \\
\hline & 黄帅蛱蝶 Sephisa princeps & 1 & & \\
\hline & 素饰蛱蝶 Stibochiona nicea & $1 、 3$ & & \\
\hline & 肃蛱蝶 Sumalia daraxa & $2 、 3$ & a & \\
\hline & 冕豹盛蛱蝶 Symbrenthia doni & 1 & & \\
\hline & 花豹盛蛱蝶 Symbrenthia hypselis & 2 & & $\sqrt{ }$ \\
\hline & 散纹盛蛱蝶 Symbrenthia lilaea & 2 & $\mathrm{ab}$ & $\sqrt{ }$ \\
\hline & 绿裙玳蛱蝶 Tanaecia julii & 3 & & \\
\hline & 猫蛱蝶 Timelaea maculata & 5 & & \\
\hline & 彩蛱蝶 Vagrans egista & 3 & & \\
\hline & 小红蛱蝶 Vanessa cardui & $1,2 、 3$ & $\mathrm{~b}$ & $\sqrt{ }$ \\
\hline & 大红蛱蝶 Vanessa indica & $2 、 3,5$ & $a b$ & $\sqrt{ }$ \\
\hline & 指名文蛱蝶 Vindula arsinoe & 5 & & \\
\hline & 文蛱蝶 Vindula erota & $2 、 3$ & a & $\sqrt{ }$ \\
\hline & 罗哈林眼蝶 Aulocera loha & 4 & & \\
\hline & 细眉林眼蝶 Aulocera merlina & 3 & & \\
\hline & 大型林眼蝶 Aulocera padma & $2 、 3$ & & $\sqrt{ }$ \\
\hline & 小型林眼蝶 Aulocera sybillina & 3 & & \\
\hline & 箭纹粉眼蝶 Callarge sagitta & 1 & & \\
\hline & 双瞳艳眼蝶 Callerebia perocellata & 3 & & \\
\hline & 大艳眼蝶 Callerebia suroia & 4 & $\mathrm{~b}$ & \\
\hline & 带眼蝶 Chonala episcopalis & 3 & & \\
\hline & 胡塔斯带眼蝶 Chonala huertasae & 1 & & \\
\hline & 棕带眼蝶 Chonala praeusta & 1 & & \\
\hline & 多眼蝶 Kirinia epaminondas & 7 & & \\
\hline & 安徒生黛眼蝶 Lethe andersoni & $1 、 3$ & & \\
\hline & 贝利黛眼蝶 Lethe baileyi & 1 & & $\sqrt{ }$ \\
\hline
\end{tabular}


易浪, 董亚坤, 苗白鸽, 彭艳琼 (2021) 云南高黎贡山地区蝴蝶群落多样性. 生物多样性, 29, 950-959. https://www.biodiversity-science.net/CN/10.17520/biods.2020486

\begin{tabular}{|c|c|c|c|c|}
\hline \multirow{3}{*}{$\begin{array}{l}\text { 科 } \\
\text { Family }\end{array}$} & \multirow{3}{*}{$\begin{array}{l}\text { 种类 } \\
\text { Species }\end{array}$} & \multicolumn{3}{|c|}{ 来源 Resources } \\
\hline & & 文献 & 馆藏标本* & 调查 \\
\hline & & Literatures & Specimens* & Investigation \\
\hline & 曲纹黛眼蝶 Lethe chandica & 7 & & \\
\hline & 白带黛眼蝶 Lethe confusa & 2,3 & $a b$ & $\sqrt{ }$ \\
\hline & 圣母黛眼蝶 Lethe cybele & 7 & & $\sqrt{ }$ \\
\hline & 黛眼蝶 Lethe dura & & $\mathrm{b}$ & $\sqrt{ }$ \\
\hline & 云纹黛眼蝶 Lethe elwesi & 1 & & \\
\hline & 长纹黛眼蝶 Lethe europa & 7 & & \\
\hline & 高帕黛眼蝶 Lethe goalpara & 1 & & \\
\hline & 七黛眼蝶 Lethe gregoryi & 1 & & \\
\hline & 宽带黛眼蝶 Lethe helena & 5 & & \\
\hline & 深山黛眼蝶 Lethe hyrania & $1,2 、 3$ & & $\sqrt{ }$ \\
\hline & 小云斑黛眼蝶 Lethe jalaurida & 2 & & \\
\hline & 甘萨黛眼蝶 Lethe kansa & & $\mathrm{a}$ & \\
\hline & 侧带黛眼蝶 Lethe latiaris & 1 & & $\sqrt{ }$ \\
\hline & 傈傈黛眼蝶 Lethe lisuae & 1 & & \\
\hline & 大纹竹眼蝶 Lethe maitnya & 3 & & \\
\hline & 迷纹黛眼蝶 Lethe maitrya & 1 & & $\sqrt{ }$ \\
\hline & 边纹黛眼蝶 Lethe marginalis & 1 & & \\
\hline & 三楔黛眼蝶 Lethe mekara & 3 & & \\
\hline & 米勒黛眼蝶 Lethe moelleri & $1 、 3$ & & \\
\hline & 锯纹黛眼蝶 Lethe nicetas & 1 & & $\sqrt{ }$ \\
\hline & 玉山黛眼蝶 Lethe niitakana & 3 & & \\
\hline & 滇缅黛眼蝶 Lethe nosei & 4 & & \\
\hline & 比目黛眼蝶 Lethe proxima & 3 & & \\
\hline & 波纹黛眼蝶 Lethe rohria & 3 & $\mathrm{~b}$ & $\sqrt{ }$ \\
\hline & 华山黛眼蝶 Lethe serbonis & & & $\sqrt{ }$ \\
\hline & 西峒黛眼蝶 Lethe sidonis & 1 & & $\sqrt{ }$ \\
\hline & 尖尾黛眼蝶 Lethe sinorix & 2 & & \\
\hline & 素拉黛眼蝶 Lethe sura & $1 、 3$ & & \\
\hline & 腾冲黛眼蝶 Lethe tengchongensis & 1 & & \\
\hline & 重瞳黛眼蝶 Lethe trimacula & 5 & & \\
\hline & 厄目黛眼蝶 Lethe umedai & 1 & & \\
\hline & 玉带黛眼蝶 Lethe verma & $1,2 、 3$ & $\mathrm{ab}$ & $\sqrt{ }$ \\
\hline & 紫线黛眼蝶 Lethe violaceopicta & 3 & & \\
\hline & 华西白眼蝶 Melanargia leda & 7 & & \\
\hline & 暮眼蝶 Melanitis leda & $1,2 、 3$ & $\mathrm{~b}$ & $\sqrt{ }$ \\
\hline & 睇暮眼蝶 Melanitis phedima & 3 & & \\
\hline & 蛇眼蝶 Minois dryas & 7 & & \\
\hline & 拟稻眉眼蝶 Mycalesis francisca & 1 & a & $\sqrt{ }$ \\
\hline & 稻眉眼蝶 Mycalesis gotama & & & $\sqrt{ }$ \\
\hline & 霍氏眉眼蝶 Mycalesis horsfieldi & 3 & & \\
\hline
\end{tabular}


易浪, 董亚坤, 苗白鸽, 彭艳琼 (2021) 云南高黎贡山地区蝴蝶群落多样性. 生物多样性, 29, 950-959. https://www.biodiversity-science.net/CN/10.17520/biods.2020486

\begin{tabular}{|c|c|c|c|c|}
\hline \multirow{3}{*}{$\begin{array}{l}\text { 科 } \\
\text { Family }\end{array}$} & \multirow{3}{*}{$\begin{array}{l}\text { 种类 } \\
\text { Species }\end{array}$} & \multicolumn{3}{|c|}{ 来源 Resources } \\
\hline & & 文献 & 馆藏标本* & 调查 \\
\hline & & Literatures & Specimens* & Investigation \\
\hline & 珞巴眉眼蝶 Mycalesis lepcha & 3 & & \\
\hline & 大理石眉眼蝶 Mycalesis mamerta & 7 & $\mathrm{a}$ & \\
\hline & 小眉眼蝶 Mycalesis mineus & 2 & $\mathrm{~b}$ & $\sqrt{ }$ \\
\hline & 密纱眉眼蝶 Mycalesis misenus & 1 & & $\sqrt{ }$ \\
\hline & 平顶眉眼蝶 Mycalesis panthaka & 2 & $\mathrm{~b}$ & \\
\hline & 裴斯眉眼蝶 Mycalesis perseus & 3 & & \\
\hline & 罕眉眼蝶 Mycalesis suavolens & 1 & & \\
\hline & 田园荫眼蝶 Neope agrestis & 1 & & \\
\hline & 阿芒荫眼蝶 Neope armandii & 1 & & \\
\hline & 网纹荫眼蝶 Neope christi & 3 & & \\
\hline & 蒙链荫眼蝶 Neope muirheadii & 3 & $a b$ & \\
\hline & 金色荫眼蝶 Neope niphonica & 3 & & \\
\hline & 奥荫眼蝶 Neope oberthueri & 1 & $\mathrm{~b}$ & \\
\hline & 普拉荫眼蝶 Neope pulahina & 1 & & \\
\hline & 黑斑荫眼蝶 Neope pulahoides & 1 & & \\
\hline & 黑翅荫眼蝶 Neope serica & & $\mathrm{a}$ & \\
\hline & 拟网纹荫眼蝶 Neope simulans & 3 & & \\
\hline & 丝链荫眼蝶 Neope yama & 3 & & \\
\hline & 凤眼蝶 Neorina partia & 2 & a & \\
\hline & 岳眼蝶 Orinoma damaris & 1 & & \\
\hline & 奥眼蝶 Orsotriaena medus & 3 & & \\
\hline & 双瞳带眼蝶 Pararge minuscula & 3 & & \\
\hline & 彩裳斑眼蝶 Penthema darlisa & 1 & $\mathrm{~b}$ & \\
\hline & 黄网眼蝶 Rhaphicera satrica & 1 & & \\
\hline & 翄眼蝶 Ypthima baldus & 1 & $\mathrm{~b}$ & $\sqrt{ }$ \\
\hline & 中华犕眼蝶 Ypthima chinensis & 2 & & $\sqrt{ }$ \\
\hline & 孔擭眼蝶 Ypthima confusa & & & $\sqrt{ }$ \\
\hline & 幽矍眼蝶 Ypthima conjuncta & 2 & & $\sqrt{ }$ \\
\hline & 重光賏眼蝶 Ypthima dromon & 3 & & \\
\hline & 台湾筧眼蝶 Ypthima formosana & & $\mathrm{b}$ & \\
\hline & 福翟眼蝶 Ypthima frontierii & 1 & & \\
\hline & 魔女筧眼蝶 Ypthima medusa & 7 & & \\
\hline & 乱云榎眼蝶 Ypthima megalomma & 2 & & \\
\hline & 小䍜眼蝶 Ypthima nareda & 7 & $\mathrm{~b}$ & \\
\hline & 融斑矍眼蝶 Ypthima nikaea & & $\mathrm{b}$ & \\
\hline & 罕翄眼蝶 Ypthima norma & 1 & & \\
\hline & 完璧翄眼蝶 Ypthima perfecta & 7 & & \\
\hline & 连斑篗眼蝶 Ypthima sakra & 1 & $\mathrm{~b}$ & $\sqrt{ }$ \\
\hline & 大波嬳眼蝶 Ypthima tappana & 1 & & $\sqrt{ }$ \\
\hline & 卓翟眼蝶 Ypthima zodia & 1,2 & & $\sqrt{ }$ \\
\hline
\end{tabular}


易浪, 董亚坤, 苗白鸽, 彭艳琼 (2021) 云南高黎贡山地区蝴蝶群落多样性. 生物多样性, 29, 950-959. https://www.biodiversity-science.net/CN/10.17520/biods.2020486

\begin{tabular}{|c|c|c|c|c|}
\hline \multirow{3}{*}{$\begin{array}{l}\text { 科 } \\
\text { Family }\end{array}$} & \multirow{3}{*}{$\begin{array}{l}\text { 种类 } \\
\text { Species }\end{array}$} & \multicolumn{3}{|c|}{ 来源 Resources } \\
\hline & & 文献 & 馆藏标本* & 调查 \\
\hline & & Literatures & Specimens* & Investigation \\
\hline & 金斑蝶 Danaus chrysippus & 3 & & $\sqrt{ }$ \\
\hline & 虎斑蝶 Danaus genutia & 3 & $a b$ & $\sqrt{ }$ \\
\hline & 黑虎斑蝶 Danaus melanippus & 2 & & \\
\hline & 蓝点紫斑蝶 Euploea midamus & 3 & & \\
\hline & 异型紫斑蝶 Euploea mulciber & $2 、 3$ & $a b$ & $\sqrt{ }$ \\
\hline & 绢斑蝶 Parantica aglea & 3 & $a b$ & \\
\hline & 黑绢斑蝶 Parantica melanea & 3 & $a b$ & $\sqrt{ }$ \\
\hline & 西藏绢斑蝶 Parantica pedonga & 4 & & \\
\hline & 大绢斑蝶 Parantica sita & $1 、 2$ & $a b$ & $\sqrt{ }$ \\
\hline & 史氏绢斑蝶 Parantica winhoei & & a & \\
\hline & 青斑蝶 Tirumala limniace & 2 & & \\
\hline & 啬青斑蝶 Tirumala septentrionis & 7 & $\mathrm{a}$ & $\sqrt{ }$ \\
\hline & 凤眼方环蝶 Discophora sondaica & 2 & & \\
\hline & 灰翅串珠环蝶 Faunis aerope & $1 、 3$ & $\mathrm{~b}$ & \\
\hline & 白㝸箭环蝶 Stichophthalma fruhstorferi & 3 & & \\
\hline & 箭环蝶 Stichophthalma howqua & 4 & & \\
\hline & 白袖箭环蝶 Stichophthalma louisa & 3 & & \\
\hline & 斯巴达星箭环蝶 Stichophthalma sparta & 1 & & \\
\hline & 棒纹喙蝶 Libythea myrrha & 3 & & \\
\hline & 芫麻珍蝶 Acraea issoria & $1,3 、 4,5$ & $\mathrm{a}$ & $\sqrt{ }$ \\
\hline 弄蝶科 & 紫斑锷弄蝶 Aeromachus catocyanea & 1 & & \\
\hline \multirow[t]{19}{*}{ Hesperiidae } & 紫点锷弄蝶 Aeromachus kali & 1 & & \\
\hline & 黑锷弄蝶 Aeromachus piceus & 1 & & \\
\hline & 黑点锷弄蝶 Aeromachus propinquus & 1 & & \\
\hline & 黄斑弄蝶 Ampittia dioscorides & 7 & & \\
\hline & 三黄斑弄蝶 Ampittia trimacula & 1 & & \\
\hline & 尖翅弄蝶 Badamia exclamationis & $1 、 3$ & & \\
\hline & 双色舟弄蝶 Barca bicolor & & a & \\
\hline & 橙翅伞弄蝶 Bibasis jaina & 2 & & \\
\hline & 黄斑银弄蝶 Carterocephalus alcinoides & 3 & & $\sqrt{ }$ \\
\hline & 斜带星弄蝶 Celaenorrhinus aurivittatus & 3,5 & & \\
\hline & 同宗星弄蝶 Celaenorrhinus consanguineus & 1 & & \\
\hline & 达娜达星弄蝶 Celaenorrhinus dhanada & 1 & & \\
\hline & 尖翅星弄蝶 Celaenorrhinus sumitra & 4 & & \\
\hline & 绿弄蝶 Choaspes benjaminii & 3 & & $\sqrt{ }$ \\
\hline & 布窗弄蝶 Coladenia buchananii & 1 & & \\
\hline & 黄窗弄蝶 Coladenia laxmi & & $\mathrm{b}$ & \\
\hline & 窗升蝶 Coladenia maeniata & 1 & & \\
\hline & 黑弄蝶 Daimio tethys & 1 & & \\
\hline & 黄斑蕉弄蝶 Erionota torus & 2 & $\mathrm{~b}$ & \\
\hline
\end{tabular}


易浪, 董亚坤, 苗白鸽, 彭艳琼 (2021) 云南高黎贡山地区蝴蝶群落多样性. 生物多样性, 29, 950-959. https://www.biodiversity-science.net/CN/10.17520/biods.2020486

\begin{tabular}{|c|c|c|c|c|}
\hline \multirow{3}{*}{$\begin{array}{l}\text { 科 } \\
\text { Family }\end{array}$} & \multirow{3}{*}{$\begin{array}{l}\text { 种类 } \\
\text { Species }\end{array}$} & \multicolumn{3}{|c|}{ 来源 Resources } \\
\hline & & 文献 & 馆藏标本* & 调查 \\
\hline & & Literatures & Specimens* & Investigation \\
\hline & 尖翅椰弄蝶 Gangara lebadea & 3 & & \\
\hline & 匪夷捷弄蝶 Gerosis phisara & 1 & & \\
\hline & 中华捷弄蝶 Gerosis sinica & & & $\sqrt{ }$ \\
\hline & 汉酣弄蝶 Halpe handa & 1 & & \\
\hline & 无趾弄蝶 Hasora anura & 1 & & \\
\hline & 纬带趾弄蝶 Hasora vitta & 3 & & \\
\hline & 双带弄蝶 Lobocla bifasciata & $1 、 3$ & a & \\
\hline & 曲纹带弄蝶 Lobocla germana & 1 & & \\
\hline & 黄带弄蝶 Lobocla liliana & & $\mathrm{b}$ & \\
\hline & 曲纹袖弄蝶 Notocrypta curvifascia & 3 & & \\
\hline & 宽纹袖弄蝶 Notocrypta feisthamelii & 1、 2 & & \\
\hline & 菩提赫弄蝶 Ochlodes bouddha & 3 & $\mathrm{~b}$ & \\
\hline & 黄赫弄蝶 Ochlodes crataeis & 1 & & \\
\hline & 雪山赫弄蝶 Ochlodes siva & 3 & & \\
\hline & 白斑㬨弄蝶 Ochlodes subhyalina & 3 & $\mathrm{~b}$ & \\
\hline & 西藏赫弄蝶 Ochlodes thibetana & 1 & & \\
\hline & 奥弄蝶 Ochus subvittatus & 1 & & \\
\hline & 角翅弄蝶 Odontoptilum angulatum & & & $\sqrt{ }$ \\
\hline & 么纹稻弄蝶 Parnara bada & & $\mathrm{b}$ & \\
\hline & 曲纹稻弄蝶 Parnara ganga & & $\mathrm{b}$ & \\
\hline & 直纹稻弄蝶 Parnara guttata & 2 & $\mathrm{~b}$ & \\
\hline & 印度谷弄蝶 Pelopidas assamensis & 2 & & \\
\hline & 隐纹谷弄蝶 Pelopidas mathias & & & $\sqrt{ }$ \\
\hline & 中华谷弄蝶 Pelopidas sinensis & 3 & & \\
\hline & 融纹孔弄蝶 Polytremis discreta & 1 & & \\
\hline & 台湾孔弄蝶 Polytremis eltola & 7 & $\mathrm{~b}$ & $\sqrt{ }$ \\
\hline & 微点孔弄蝶 Polytremis gotama & 1 & & \\
\hline & 松井孔弄蝶 Polytremis matsuii & 1 & & \\
\hline & 怒江孔弄蝶 Polytremis micropunctata & 1 & & \\
\hline & 孔子黄室弄蝶 Potanthus confucius & 2 & & $\sqrt{ }$ \\
\hline & 曲纹黄室弄蝶 Potanthus flavus & $1 、 2$ & & \\
\hline & 锯纹黄室弄蝶 Potanthus lydius & 7 & & \\
\hline & 玛拉黄室弄蝶 Potanthus mara & 1 & & \\
\hline & 淡色黄室弄蝶 Potanthus pallidus & & $\mathrm{b}$ & \\
\hline & 尖翅黄室弄蝶 Potanthus palnia & & & $\sqrt{ }$ \\
\hline & 拟籼弄蝶 Pseudoborbo bevani & 1 & & \\
\hline & 黄襟弄蝶 Pseudocoladenia dan & 7 & & $\sqrt{ }$ \\
\hline & 密带襟弄蝶 Pseudocoladenia festa & 1 & & \\
\hline & 花弄蝶 Pyrgus maculatus & 3 & & \\
\hline & 西藏飒弄蝶 Satarupa zulla & 1 & & \\
\hline
\end{tabular}


易浪, 董亚坤, 苗白鸽, 彭艳琼 (2021) 云南高黎贡山地区蝴蝶群落多样性. 生物多样性, 29, 950-959. https://www.biodiversity-science.net/CN/10.17520/biods.2020486

\begin{tabular}{|c|c|c|c|c|}
\hline \multirow{3}{*}{$\begin{array}{l}\text { 科 } \\
\text { Family }\end{array}$} & \multirow{3}{*}{$\begin{array}{l}\text { 种类 } \\
\text { Species }\end{array}$} & \multicolumn{3}{|c|}{ 来源 Resources } \\
\hline & & 文献 & 馆藏标本* & 调查 \\
\hline & & Literatures & Specimens* & Investigation \\
\hline & 斜带弄蝶 Sebastonyma dolopia & 1 & & \\
\hline & 暗缘㥰弄蝶 Sovia grahami & 1 & & $\sqrt{ }$ \\
\hline & 错缘㥰弄蝶 Sovia separata & 1 & & \\
\hline & 贝利陀弄蝶 Thoressa baileyi & 1 & & \\
\hline & 凹瓣陀弄蝶 Thoressa fusca & 1 & & \\
\hline & 无标陀弄蝶 Thoressa pandita & 1 & & \\
\hline & 侏儒陀弄蝶 Thoressa pedla & 1 & & \\
\hline & 赛陀弄蝶 Thoressa serena & 1 & & \\
\hline & 白斑弄蝶 Tsukiyamaia albimacula & 1 & & \\
\hline & 姜弄蝶 Udaspes folus & 2 & & $\sqrt{ }$ \\
\hline
\end{tabular}

文献出处1-7 见后面参考文献。*标本 $\mathrm{a}$ 代表保山学院馆藏标本, $\mathrm{b}$ 代表昆明动物所馆藏标本, $\sqrt{ }$ 代 表本研究调查到的种类。 
易浪, 董亚坤, 苗白鸽, 彭艳琼 (2021) 云南高黎贡山地区蝴蝶群落多样性. 生物多样性, 29, 950-959. https://www.biodiversity-science.net/CN/10.17520/biods.2020486

\section{参考文献}

[1] Wu CS, Hsu YF (2017) Butterflies of China. Straits Publishing House, Fuzhou. (in Chinese) [武 春生, 徐堉峰 (2017) 中国蝴蝶图鉴. 海峡书局, 福州.]

[2] Ou XH, Yang CQ, Song JX, Xiong J (2005) Survey and analysis of butterfly diversity in Gaoligongshan National Nature Reserve. In: Proceedings of the Sixth National Symposium on the Conservation and Sustainable Use of Biodiversity in China (ed. Ma KP), pp. 178-187. Meteorological Press, Beijing. (in Chinese) [欧晓红, 杨春清, 宋劲忻, 熊江 (2005) 高黎贡山 自然保护区蝶类多样性的调查与分析. 见: 第六届全国生物多样性保护与持续利用研讨会 论文集(马克平主编), 178-187页. 气象出版社，北京.]

[3] Dong DZ, Kavanaugh DH, Li H (2002) Butterfly resources of Nujiang Canyon in Yunnan. Journal of Southwest Agricultural University, 24, 289-292. (in Chinese with English abstract) [董 大志, 大卫.卡凡诺, 李恒 (2002) 云南怒江峡谷的蝴蝶资源. 西南农业大学学报, 24 , 289-292.]

[4] Images Biodiversity Expedition, Gaoligong Nature Reserve Nujiang Administration in Yunnan (2016) Manual of Natural Observation on Gaoligong Mountain in Nujian. Encyclopedia of China Publishing House, Beijing. (in Chinese) [影像生物调查所(IBE), 云南高黎贡山国家级自然保 护区怒江管理局 (2016) 怒江高黎贡山自然观察手册. 中国大百科全书出版社, 北京.]

[5] Liu L, Gao HP (2014) Preliminary investigation of butterfly species in mountain natural protection high Li. Journal of Baoshan University, 33(2), 10-17. (in Chinese with English abstract) [刘莉, 高焕平 (2014) 高黎贡山百花岭地区蝴蝶种类的初步调查. 保山学院学报, $33(2), 10-17$.

[6] Liu L (2016) Investigation of species of Pieridae insects and population dynamics of dominant species in Baihualing area of Gaoligong Mountain. Journal of Baoshan University, 35(5), 11-13. (in Chinese with English abstract) [刘莉 (2016) 高黎贡山百花岭地区粉蝶科昆虫种类及其优 势种种群动态调查. 保山学院学报, 35(5), 11-13.]

[7] Zhang PY (2011) Ecological Photograph Handbook of Insects in Gaoligongshan. Northest Forestry University, Haerbin. (in Chinese) [张培毅 (2011) 高黎贡山昆虫生态图鉴. 东北林业 大学出版社, 哈尔滨.] 
易浪, 董亚坤, 苗白鸽, 彭艳琼 (2021) 云南高黎贡山地区蝴蝶群落多样性. 生物多样性, 29, 950-959. https://www.biodiversity-science.net/CN/10.17520/biods.2020486

\section{附录2 云南高黎贡山地区127条蝴蝶调查样线分布图}

Appendix 2 Distribution of 127 transects for butterfly survey in Gaoligong region of Yunnan

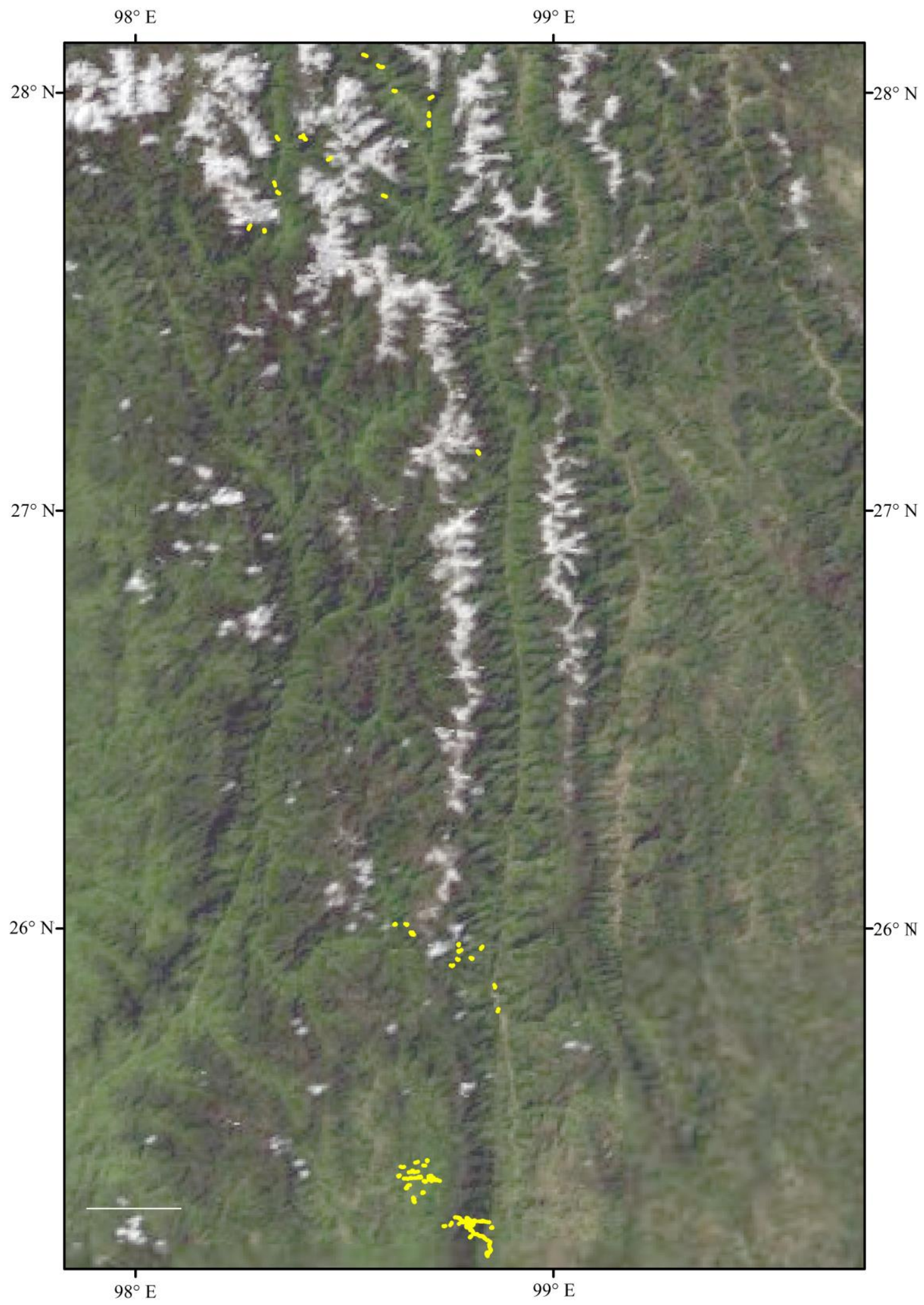


易浪, 董亚坤, 苗白鸽, 彭艳琼 (2021) 云南高黎贡山地区蝴蝶群落多样性. 生物多样性, 29, 950-959. https://www.biodiversity-science.net/CN/10.17520/biods.2020486

附录3 云南高黎贡山地区观测到的蝴蝶物种分布格局

Appendix 3 Distribution pattern of investigated butterflies in Gaoligong region of Yunnan

\begin{tabular}{|c|c|c|c|c|c|c|c|c|c|c|c|}
\hline \multirow{3}{*}{$\begin{array}{l}\text { 科名 } \\
\text { Family }\end{array}$} & \multirow{3}{*}{$\begin{array}{l}\text { 种类 } \\
\text { Species }\end{array}$} & \multicolumn{3}{|c|}{ 海拔 Altitude (m) } & \multicolumn{3}{|c|}{ 生境 Habitat } & \multicolumn{4}{|c|}{ 季节 Season } \\
\hline & & & & & 保护区 & 边缘交错带 & 农业种植区 & 2019 & 2020 & 2020 & 2020 \\
\hline & & $-1,000$ & $1,000-2,000$ & 2,000 & Reservation & Ecotone & Farm & 秋季 & 春季 & 夏季 & 秋季 \\
\hline 粉蝶科 & 迁粉蝶 Catopsilia pomona & $\sqrt{ }$ & $\sqrt{ }$ & & & $\sqrt{ }$ & $\sqrt{ }$ & $\sqrt{ }$ & $\sqrt{ }$ & $\sqrt{ }$ & $\sqrt{ }$ \\
\hline \multirow[t]{20}{*}{ Pieridae } & 青园粉蝶 Cepora nadina & $\sqrt{ }$ & & & & $\sqrt{ }$ & & & $\sqrt{ }$ & & \\
\hline & 黑脉园粉蝶 Cepora nerissa & $\sqrt{ }$ & $\sqrt{ }$ & & & $\sqrt{ }$ & $\sqrt{ }$ & & $\sqrt{ }$ & $\sqrt{ }$ & \\
\hline & 橙黄豆粉蝶 Colias fieldii & & $\sqrt{ }$ & & & & $\sqrt{ }$ & & $\sqrt{ }$ & & \\
\hline & 红腋斑粉蝶 Delias acalis & & $\sqrt{ }$ & & & $\sqrt{ }$ & & $\sqrt{ }$ & & & \\
\hline & 艳妇斑粉蝶 Delias belladonna & & $\sqrt{ }$ & & $\sqrt{ }$ & & & $\sqrt{ }$ & & & $\sqrt{ }$ \\
\hline & 优越斑粉蝶 Delias hyparete & $\sqrt{ }$ & & & & & $\sqrt{ }$ & $\sqrt{ }$ & & & \\
\hline & 报喜斑粉蝶 Delias pasithoe & $\sqrt{ }$ & & & & & $\sqrt{ }$ & $\sqrt{ }$ & & & \\
\hline & 隐条斑粉蝶 Delias subnubila & & $\sqrt{ }$ & & $\sqrt{ }$ & & & $\sqrt{ }$ & & & \\
\hline & 黑角方粉蝶 Dercas lycorias & & $\sqrt{ }$ & & $\sqrt{ }$ & & & & & $\sqrt{ }$ & \\
\hline & 安迪黄粉蝶 Eurema andersoni & $\sqrt{ }$ & $\sqrt{ }$ & & & $\sqrt{ }$ & $\sqrt{ }$ & $\sqrt{ }$ & & $\sqrt{ }$ & $\sqrt{ }$ \\
\hline & 檗黄粉蝶 Eurema blanda & $\sqrt{ }$ & $\sqrt{ }$ & & $\sqrt{ }$ & $\sqrt{ }$ & $\sqrt{ }$ & $\sqrt{ }$ & & $\sqrt{ }$ & \\
\hline & 无标黄粉蝶 Eurema brigitta & $\sqrt{ }$ & $\sqrt{ }$ & & $\sqrt{ }$ & $\sqrt{ }$ & $\sqrt{ }$ & $\sqrt{ }$ & & & $\sqrt{ }$ \\
\hline & 宽边黄粉蝶 Eurema hecabe & $\sqrt{ }$ & $\sqrt{ }$ & & $\sqrt{ }$ & $\sqrt{ }$ & $\sqrt{ }$ & $\sqrt{ }$ & $\sqrt{ }$ & $\sqrt{ }$ & $\sqrt{ }$ \\
\hline & 尖角黄粉蝶 Eurema laeta & & $\sqrt{ }$ & & & $\sqrt{ }$ & $\sqrt{ }$ & & $\sqrt{ }$ & & \\
\hline & 北黄粉蝶 Eurema mandarina & & $\sqrt{ }$ & & & & $\sqrt{ }$ & & & & $\sqrt{ }$ \\
\hline & 鹤顶粉蝶 Hebomoia glaucippe & $\sqrt{ }$ & $\sqrt{ }$ & & $\sqrt{ }$ & $\sqrt{ }$ & & & $\sqrt{ }$ & & \\
\hline & 橙粉蝶 Ixias pyrene & $\sqrt{ }$ & $\sqrt{ }$ & & $\sqrt{ }$ & $\sqrt{ }$ & $\sqrt{ }$ & $\sqrt{ }$ & $\sqrt{ }$ & $\sqrt{ }$ & $\sqrt{ }$ \\
\hline & 欧洲粉蝶 Pieris brassicae & & $\sqrt{ }$ & & & $\sqrt{ }$ & & $\sqrt{ }$ & $\sqrt{ }$ & & \\
\hline & 东方菜粉蝶 Pieris canidia & $\sqrt{ }$ & $\sqrt{ }$ & $\sqrt{ }$ & $\sqrt{ }$ & $\sqrt{ }$ & $\sqrt{ }$ & $\sqrt{ }$ & $\sqrt{ }$ & $\sqrt{ }$ & $\sqrt{ }$ \\
\hline & 黑纹粉蝶 Pieris melete & & $\sqrt{ }$ & & $\sqrt{ }$ & $\sqrt{ }$ & $\sqrt{ }$ & & $\sqrt{ }$ & & $\sqrt{ }$ \\
\hline
\end{tabular}


易浪, 董亚坤, 苗白鸽, 彭艳琼 (2021) 云南高黎贡山地区蝴蝶群落多样性. 生物多样性, 29, 950-959. https://www.biodiversity-science.net/CN/10.17520/biods.2020486

\begin{tabular}{|c|c|c|c|c|c|c|c|c|c|c|c|}
\hline \multirow{3}{*}{$\begin{array}{l}\text { 科名 } \\
\text { Family }\end{array}$} & \multirow{3}{*}{$\begin{array}{l}\text { 种类 } \\
\text { Species }\end{array}$} & \multicolumn{3}{|c|}{ 海拔 Altitude (m) } & \multicolumn{3}{|c|}{ 生境 Habitat } & \multicolumn{4}{|c|}{ 季节 Season } \\
\hline & & -1000 & $1000 \Omega 000$ & \ 2000 & 保护区 & 边缘交错带 & 农业种植区 & 2019 & 2020 & 2020 & 2020 \\
\hline & & $-1,000$ & $1,000-2,000$ & 2,000 & Reservation & Ecotone & Farm & 秋季 & 春季 & 夏季 & 秋季 \\
\hline & 菜粉蝶 Pieris rapae & $\sqrt{ }$ & $\sqrt{ }$ & & $\sqrt{ }$ & $\sqrt{ }$ & $\sqrt{ }$ & $\sqrt{ }$ & $\sqrt{ }$ & $\sqrt{ }$ & $\sqrt{ }$ \\
\hline & 云粉蝶 Pontia edusa & $\sqrt{ }$ & $\sqrt{ }$ & & & $\sqrt{ }$ & $\sqrt{ }$ & $\sqrt{ }$ & $\sqrt{ }$ & $\sqrt{ }$ & $\sqrt{ }$ \\
\hline 凤蝶科 & 多尾凤蝶 Bhutanitis lidderdalii & & $\sqrt{ }$ & & $\sqrt{ }$ & & & $\sqrt{ }$ & & & $\sqrt{ }$ \\
\hline \multirow[t]{9}{*}{ Papilionidae } & 多姿廂凤蝶 Byasa polyeuetes & & $\sqrt{ }$ & & & & $\sqrt{ }$ & & $\sqrt{ }$ & & \\
\hline & 青凤蝶 Graphium sarpedon & & $\sqrt{ }$ & & & $\sqrt{ }$ & & & & & $\sqrt{ }$ \\
\hline & 碧凤蝶 Papilio bianor & $\sqrt{ }$ & $\sqrt{ }$ & & $\sqrt{ }$ & $\sqrt{ }$ & $\sqrt{ }$ & $\sqrt{ }$ & & $\sqrt{ }$ & $\sqrt{ }$ \\
\hline & 达摩凤蝶 Papilio demoleus & $\sqrt{ }$ & & & & $\sqrt{ }$ & $\sqrt{ }$ & $\sqrt{ }$ & $\sqrt{ }$ & $\sqrt{ }$ & \\
\hline & 玉斑凤蝶 Papilio helenus & $\sqrt{ }$ & $\sqrt{ }$ & & $\sqrt{ }$ & $\sqrt{ }$ & $\sqrt{ }$ & $\sqrt{ }$ & $\sqrt{ }$ & $\sqrt{ }$ & \\
\hline & 巴黎翠凤蝶 Papilio paris & & $\sqrt{ }$ & & $\sqrt{ }$ & $\sqrt{ }$ & & $\sqrt{ }$ & & & \\
\hline & 玉带凤蝶 Papilio polytes & $\sqrt{ }$ & $\sqrt{ }$ & & $\sqrt{ }$ & $\sqrt{ }$ & & & & $\sqrt{ }$ & \\
\hline & 柑橘凤蝶 Papilio xuthus & $\sqrt{ }$ & $\sqrt{ }$ & & & $\sqrt{ }$ & $\sqrt{ }$ & $\sqrt{ }$ & & & $\sqrt{ }$ \\
\hline & 金裳凤蝶 Troides aeacus & & $\sqrt{ }$ & & $\sqrt{ }$ & $\sqrt{ }$ & $\sqrt{ }$ & $\sqrt{ }$ & & $\sqrt{ }$ & \\
\hline 灰蝶科 & 钮灰蝶 Acytolepis puspa & & $\sqrt{ }$ & $\sqrt{ }$ & $\sqrt{ }$ & $\sqrt{ }$ & & $\sqrt{ }$ & & $\sqrt{ }$ & $\sqrt{ }$ \\
\hline \multirow[t]{10}{*}{ Lycaenidae } & 百娆灰蝶 Arhopala bazala & & & $\sqrt{ }$ & $\sqrt{ }$ & & & $\sqrt{ }$ & & & \\
\hline & 散纹拓灰蝶 Caleta elna & $\sqrt{ }$ & & & & & $\sqrt{ }$ & $\sqrt{ }$ & & & \\
\hline & 豹灰蝶 Castalius rosimon & $\sqrt{ }$ & & & & $\sqrt{ }$ & $\sqrt{ }$ & $\sqrt{ }$ & & & $\sqrt{ }$ \\
\hline & 咖灰蝶 Catochrysops strabo & $\sqrt{ }$ & $\sqrt{ }$ & & $\sqrt{ }$ & $\sqrt{ }$ & $\sqrt{ }$ & $\sqrt{ }$ & & $\sqrt{ }$ & $\sqrt{ }$ \\
\hline & 琉璃灰蝶 Celastrina argiola & & $\sqrt{ }$ & & & $\sqrt{ }$ & $\sqrt{ }$ & & & $\sqrt{ }$ & $\sqrt{ }$ \\
\hline & 大紫琉璃灰蝶 Celastrina oreas & & $\sqrt{ }$ & & $\sqrt{ }$ & & & $\sqrt{ }$ & & & \\
\hline & 暳玉灰蝶 Celatoxia marginata & & $\sqrt{ }$ & & & $\sqrt{ }$ & & $\sqrt{ }$ & & & \\
\hline & 紫灰蝶 Chilades lajus & $\sqrt{ }$ & $\sqrt{ }$ & & & & $\sqrt{ }$ & $\sqrt{ }$ & & & \\
\hline & 曲纹紫灰蝶 Chilades pandava & $\sqrt{ }$ & & & & & $\sqrt{ }$ & $\sqrt{ }$ & & & \\
\hline & 普紫灰蝶 Chilades putli & $\sqrt{ }$ & & & & & $\sqrt{ }$ & $\sqrt{ }$ & & & \\
\hline
\end{tabular}


易浪, 董亚坤, 苗白鸽, 彭艳琼 (2021) 云南高黎贡山地区蝴蝶群落多样性. 生物多样性, 29, 950-959. https://www.biodiversity-science.net/CN/10.17520/biods.2020486

\begin{tabular}{|c|c|c|c|c|c|c|c|c|c|c|c|}
\hline \multirow{3}{*}{$\begin{array}{l}\text { 科名 } \\
\text { Family }\end{array}$} & \multirow{3}{*}{$\begin{array}{l}\text { 种类 } \\
\text { Species }\end{array}$} & \multicolumn{3}{|c|}{ 海拔 Altitude (m) } & \multicolumn{3}{|c|}{ 生境 Habitat } & \multicolumn{4}{|c|}{ 季节 Season } \\
\hline & & - & & $>0$ & 保护区 & 边缘交错带 & 农业种植区 & 2019 & 2020 & 2020 & 2020 \\
\hline & & $-1,000$ & $1,000-2,000$ & 2,000 & Reservation & Ecotone & Farm & 秋季 & 春季 & 夏季 & 秋季 \\
\hline & 尖翅银灰蝶 Curetis acuta & & & $\sqrt{ }$ & $\sqrt{ }$ & & & & & & $\sqrt{ }$ \\
\hline & 蓝灰蝶 Everes argiades & & $\sqrt{ }$ & & $\sqrt{ }$ & & & $\sqrt{ }$ & & & \\
\hline & 美男彩灰蝶 Heliophorus androcles & & $\sqrt{ }$ & & $\sqrt{ }$ & & & & & & $\sqrt{ }$ \\
\hline & 古铜彩灰蝶 Heliophorus brahma & & $\sqrt{ }$ & $\sqrt{ }$ & $\sqrt{ }$ & $\sqrt{ }$ & $\sqrt{ }$ & $\sqrt{ }$ & $\sqrt{ }$ & & $\sqrt{ }$ \\
\hline & 依彩灰蝶 Heliophorus eventa & & $\sqrt{ }$ & $\sqrt{ }$ & $\sqrt{ }$ & & & & $\sqrt{ }$ & $\sqrt{ }$ & \\
\hline & 浓紫彩灰蝶 Heliophorus ila & & $\sqrt{ }$ & & $\sqrt{ }$ & $\sqrt{ }$ & & $\sqrt{ }$ & & $\sqrt{ }$ & $\sqrt{ }$ \\
\hline & 素雅灰蝶 Jamides alecto & $\sqrt{ }$ & & & & & $\sqrt{ }$ & $\sqrt{ }$ & & & \\
\hline & 雅灰蝶 Jamides bochus & $\sqrt{ }$ & & & & & $\sqrt{ }$ & $\sqrt{ }$ & & & \\
\hline & 亮灰蝶 Lampides boeticus & $\sqrt{ }$ & $\sqrt{ }$ & & $\sqrt{ }$ & $\sqrt{ }$ & $\sqrt{ }$ & $\sqrt{ }$ & $\sqrt{ }$ & $\sqrt{ }$ & $\sqrt{ }$ \\
\hline & 细灰蝶 Leptotes plinius & $\sqrt{ }$ & & & & $\sqrt{ }$ & $\sqrt{ }$ & $\sqrt{ }$ & & $\sqrt{ }$ & \\
\hline & 鹿灰蝶 Loxura atymnus & $\sqrt{ }$ & $\sqrt{ }$ & & & & $\sqrt{ }$ & $\sqrt{ }$ & & & $\sqrt{ }$ \\
\hline & 锯灰蝶 Orthomiella pontis & & $\sqrt{ }$ & & $\sqrt{ }$ & & & & $\sqrt{ }$ & & \\
\hline & 疑波灰蝶 Prosotas dubiosa & $\sqrt{ }$ & $\sqrt{ }$ & & $\sqrt{ }$ & & $\sqrt{ }$ & & & $\sqrt{ }$ & \\
\hline & 娜拉波灰蝶 Prosotas nora & $\sqrt{ }$ & & & & & $\sqrt{ }$ & & & $\sqrt{ }$ & \\
\hline & 酢浆灰蝶 Pseudozizeeria maha & $\sqrt{ }$ & $\sqrt{ }$ & & $\sqrt{ }$ & $\sqrt{ }$ & $\sqrt{ }$ & $\sqrt{ }$ & $\sqrt{ }$ & $\sqrt{ }$ & $\sqrt{ }$ \\
\hline & 生灰蝶 Sinthusa chandrana & & $\sqrt{ }$ & & & $\sqrt{ }$ & $\sqrt{ }$ & $\sqrt{ }$ & $\sqrt{ }$ & & \\
\hline & 银线灰蝶 Spindasis lohita & $\sqrt{ }$ & & & & $\sqrt{ }$ & & & $\sqrt{ }$ & & \\
\hline & 豆粒银线灰蝶 Spindasis syama & & $\sqrt{ }$ & & $\sqrt{ }$ & & & & & & $\sqrt{ }$ \\
\hline & 凯丽藤灰蝶 Tarucus callinara & $\sqrt{ }$ & & & & $\sqrt{ }$ & & & & & $\sqrt{ }$ \\
\hline & 珍贵妩灰蝶 Udara dilecta & & $\sqrt{ }$ & & $\sqrt{ }$ & $\sqrt{ }$ & $\sqrt{ }$ & $\sqrt{ }$ & $\sqrt{ }$ & $\sqrt{ }$ & \\
\hline & 吉灰蝶 Zizeeria karsandra & $\sqrt{ }$ & $\sqrt{ }$ & & $\sqrt{ }$ & $\sqrt{ }$ & $\sqrt{ }$ & $\sqrt{ }$ & $\sqrt{ }$ & & \\
\hline & 毛眼灰蝶 Zizina otis & $\sqrt{ }$ & $\sqrt{ }$ & & & $\sqrt{ }$ & $\sqrt{ }$ & $\sqrt{ }$ & $\sqrt{ }$ & & $\sqrt{ }$ \\
\hline & 长腹灰蝶 Zizula hylax & & $\sqrt{ }$ & & & & $\sqrt{ }$ & $\sqrt{ }$ & & & \\
\hline
\end{tabular}


易浪, 董亚坤, 苗白鸽, 彭艳琼 (2021) 云南高黎贡山地区蝴蝶群落多样性. 生物多样性, 29, 950-959. https://www.biodiversity-science.net/CN/10.17520/biods.2020486

\begin{tabular}{|c|c|c|c|c|c|c|c|c|c|c|c|}
\hline \multirow{3}{*}{$\begin{array}{l}\text { 科名 } \\
\text { Family }\end{array}$} & \multirow{3}{*}{$\begin{array}{l}\text { 种类 } \\
\text { Species }\end{array}$} & \multicolumn{3}{|c|}{ 海拔 Altitude (m) } & \multicolumn{3}{|c|}{ 生境 Habitat } & \multicolumn{4}{|c|}{ 季节 Season } \\
\hline & & \multirow{2}{*}{$<1,000$} & \multirow{2}{*}{$1,000-2,000$} & \multirow{2}{*}{$>2,000$} & \multirow{2}{*}{$\begin{array}{c}\text { 保护区 } \\
\text { Reservation }\end{array}$} & \multirow{2}{*}{$\begin{array}{c}\text { 边缘交错带 } \\
\text { Ecotone }\end{array}$} & \multirow{2}{*}{$\begin{array}{c}\text { 农业种植区 } \\
\text { Farm }\end{array}$} & \multirow{2}{*}{$\begin{array}{l}2019 \\
\text { 秋季 }\end{array}$} & \multirow{2}{*}{$\begin{array}{l}2020 \\
\text { 春季 }\end{array}$} & \multirow{2}{*}{$\begin{array}{l}2020 \\
\text { 夏季 }\end{array}$} & \multirow{2}{*}{$\begin{array}{l}2020 \\
\text { 秋季 }\end{array}$} \\
\hline & & & & & & & & & & & \\
\hline & 方裙蝎蚬蝶 Abisara freda & & $\sqrt{ }$ & & $\sqrt{ }$ & & & $\sqrt{ }$ & & & \\
\hline & 黄带褐蚬蝶 Abisara fylla & & $\sqrt{ }$ & & $\sqrt{ }$ & $\sqrt{ }$ & & $\sqrt{ }$ & $\sqrt{ }$ & $\sqrt{ }$ & $\sqrt{ }$ \\
\hline & 白带褐蚬蝶 Abisara fylloides & $\sqrt{ }$ & & & & & $\sqrt{ }$ & $\sqrt{ }$ & & & \\
\hline & 红秃尾蚬蝶 Dodona adonira & & & $\sqrt{ }$ & $\sqrt{ }$ & & & $\sqrt{ }$ & & & \\
\hline & 黑燕尾蚬蝶 Dodona deodata & & $\sqrt{ }$ & & & $\sqrt{ }$ & & & & & $\sqrt{ }$ \\
\hline & 秃尾蚬蝶 Dodona dipoea & & $\sqrt{ }$ & & $\sqrt{ }$ & & & $\sqrt{ }$ & & & \\
\hline & 大斑尾蚬蝶 Dodona egeon & & & $\sqrt{ }$ & $\sqrt{ }$ & & & & & & $\sqrt{ }$ \\
\hline & 银纹尾蚬蝶 Dodona eugenes & & $\sqrt{ }$ & $\sqrt{ }$ & $\sqrt{ }$ & $\sqrt{ }$ & $\sqrt{ }$ & $\sqrt{ }$ & $\sqrt{ }$ & $\sqrt{ }$ & $\sqrt{ }$ \\
\hline & 斜带缺尾蚬蝶 Dodona ouida & & & $\sqrt{ }$ & $\sqrt{ }$ & & & $\sqrt{ }$ & & & \\
\hline & 波蚬蝶 Zemeros flegyas & & $\sqrt{ }$ & $\sqrt{ }$ & $\sqrt{ }$ & $\sqrt{ }$ & $\sqrt{ }$ & $\sqrt{ }$ & $\sqrt{ }$ & $\sqrt{ }$ & $\sqrt{ }$ \\
\hline 蛱蝶科 & 直纹蜘蛱蝶 Araschnia prorsoides & & $\sqrt{ }$ & $\sqrt{ }$ & $\sqrt{ }$ & & & & $\sqrt{ }$ & $\sqrt{ }$ & $\sqrt{ }$ \\
\hline \multirow[t]{12}{*}{ Nymphalidae } & 斐豹蛱蝶 Argyreus hyperbius & $\sqrt{ }$ & $\sqrt{ }$ & & & $\sqrt{ }$ & $\sqrt{ }$ & $\sqrt{ }$ & $\sqrt{ }$ & & \\
\hline & 波蛱蝶 Ariadne ariadne & $\sqrt{ }$ & $\sqrt{ }$ & $\sqrt{ }$ & $\sqrt{ }$ & $\sqrt{ }$ & $\sqrt{ }$ & $\sqrt{ }$ & $\sqrt{ }$ & $\sqrt{ }$ & $\sqrt{ }$ \\
\hline & 玉杵带蛱蝶 Athyma jina & & $\sqrt{ }$ & & & $\sqrt{ }$ & & & & & $\sqrt{ }$ \\
\hline & 相思带蛱蝶 Athyma nefte & & $\sqrt{ }$ & & & $\sqrt{ }$ & & & & & $\sqrt{ }$ \\
\hline & 虬眉带蛱蝶 Athyma opalina & & & $\sqrt{ }$ & $\sqrt{ }$ & & & $\sqrt{ }$ & & $\sqrt{ }$ & \\
\hline & 玄珠带蛱蝶 Athyma perius & $\sqrt{ }$ & & & & & $\sqrt{ }$ & $\sqrt{ }$ & & & \\
\hline & 红锯蛱蝶 Cethosia biblis & $\sqrt{ }$ & $\sqrt{ }$ & & $\sqrt{ }$ & $\sqrt{ }$ & $\sqrt{ }$ & $\sqrt{ }$ & $\sqrt{ }$ & & $\sqrt{ }$ \\
\hline & 黄绢坎蛱蝶 Chersonesia risa & $\sqrt{ }$ & & & & & $\sqrt{ }$ & & & & $\sqrt{ }$ \\
\hline & 银豹蛱蝶 Childrena childreni & $\sqrt{ }$ & & $\sqrt{ }$ & $\sqrt{ }$ & $\sqrt{ }$ & $\sqrt{ }$ & $\sqrt{ }$ & & $\sqrt{ }$ & $\sqrt{ }$ \\
\hline & 幸运辘蛱蝶 Cirrochroa tyche & & $\sqrt{ }$ & & $\sqrt{ }$ & & & & & $\sqrt{ }$ & \\
\hline & 青豹蛱蝶 Damora sagana & & $\sqrt{ }$ & & & & $\sqrt{ }$ & & & & $\sqrt{ }$ \\
\hline & 茬藜纹脉蛱蝶 Hestina nama & & $\sqrt{ }$ & & & $\sqrt{ }$ & & $\sqrt{ }$ & & & \\
\hline
\end{tabular}


易浪, 董亚坤, 苗白鸽, 彭艳琼 (2021) 云南高黎贡山地区蝴蝶群落多样性. 生物多样性, 29, 950-959. https://www.biodiversity-science.net/CN/10.17520/biods.2020486

\begin{tabular}{|c|c|c|c|c|c|c|c|c|c|c|c|}
\hline \multirow{3}{*}{$\begin{array}{l}\text { 科名 } \\
\text { Family }\end{array}$} & \multirow{3}{*}{$\begin{array}{l}\text { 种类 } \\
\text { Species }\end{array}$} & \multicolumn{3}{|c|}{ 海拔 Altitude (m) } & \multicolumn{3}{|c|}{ 生境 Habitat } & \multicolumn{4}{|c|}{ 季节 Season } \\
\hline & & $>1000$ & 10002000 & ל > & 保护区 & 边缘交错带 & 农业种植区 & 2019 & 2020 & 2020 & 2020 \\
\hline & & $-1,000$ & $1,000-2,000$ & 2,000 & Reservation & Ecotone & Farm & 秋季 & 春季 & 夏季 & 秋季 \\
\hline & 幻紫斑蛱蝶 Hypolimnas bolina & & $\sqrt{ }$ & & & $\sqrt{ }$ & & $\sqrt{ }$ & & & \\
\hline & 美眼蛱蝶 Junonia almana & $\sqrt{ }$ & & $\sqrt{ }$ & $\sqrt{ }$ & $\sqrt{ }$ & & & $\sqrt{ }$ & & $\sqrt{ }$ \\
\hline & 黄裳眼蛱蝶 Junonia hierta & $\sqrt{ }$ & $\sqrt{ }$ & & & & $\sqrt{ }$ & $\sqrt{ }$ & $\sqrt{ }$ & & \\
\hline & 钩翅眼蛱蝶 Junonia iphita & $\sqrt{ }$ & & & & $\sqrt{ }$ & & & $\sqrt{ }$ & & \\
\hline & 蛇眼蛱蝶 Junonia lemonias & $\sqrt{ }$ & & & & & $\sqrt{ }$ & $\sqrt{ }$ & & & \\
\hline & 翠蓝眼蛱蝶 Junonia orithya & $\sqrt{ }$ & $\sqrt{ }$ & $\sqrt{ }$ & $\sqrt{ }$ & $\sqrt{ }$ & $\sqrt{ }$ & & $\sqrt{ }$ & $\sqrt{ }$ & \\
\hline & 琉璃蛱蝶 Kaniska canace & & $\sqrt{ }$ & & & $\sqrt{ }$ & & & $\sqrt{ }$ & & \\
\hline & 中环蛱蝶 Neptis hylas & $\sqrt{ }$ & $\sqrt{ }$ & & & $\sqrt{ }$ & $\sqrt{ }$ & $\sqrt{ }$ & $\sqrt{ }$ & & $\sqrt{ }$ \\
\hline & 小环蛱蝶 Neptis sappho & $\sqrt{ }$ & $\sqrt{ }$ & $\sqrt{ }$ & $\sqrt{ }$ & $\sqrt{ }$ & $\sqrt{ }$ & $\sqrt{ }$ & $\sqrt{ }$ & & $\sqrt{ }$ \\
\hline & 西藏俳蛱蝶 Parasarpa zayla & & & $\sqrt{ }$ & $\sqrt{ }$ & & & & & & $\sqrt{ }$ \\
\hline & 珐蛱蝶 Phalanta phalantha & $\sqrt{ }$ & & & & & $\sqrt{ }$ & $\sqrt{ }$ & & & \\
\hline & 凤尾蛱蝶 Polyura arja & & $\sqrt{ }$ & & & $\sqrt{ }$ & & $\sqrt{ }$ & & & \\
\hline & 秀蛱蝶 Pseudergolis wedah & & $\sqrt{ }$ & $\sqrt{ }$ & $\sqrt{ }$ & $\sqrt{ }$ & & $\sqrt{ }$ & & & $\sqrt{ }$ \\
\hline & 花豹盛蛱蝶 Symbrenthia hypselis & & $\sqrt{ }$ & & $\sqrt{ }$ & & & $\sqrt{ }$ & & & \\
\hline & 散纹盛蛱蝶 Symbrenthia liaea & $\sqrt{ }$ & $\sqrt{ }$ & & $\sqrt{ }$ & & $\sqrt{ }$ & $\sqrt{ }$ & & & $\sqrt{ }$ \\
\hline & 啬青斑蝶 Tirumala septentrionis & $\sqrt{ }$ & & & & & $\sqrt{ }$ & $\sqrt{ }$ & & & \\
\hline & 小红蛱蝶 Vanessa cardui & & $\sqrt{ }$ & & $\sqrt{ }$ & $\sqrt{ }$ & $\sqrt{ }$ & $\sqrt{ }$ & $\sqrt{ }$ & & \\
\hline & 大红蛱蝶 Vanessa indica & & $\sqrt{ }$ & & & $\sqrt{ }$ & & & $\sqrt{ }$ & & \\
\hline & 文蛱蝶 Vindula erota & $\sqrt{ }$ & $\sqrt{ }$ & & & & $\sqrt{ }$ & $\sqrt{ }$ & & & \\
\hline & 大型林眼蝶 Aulocera padma & & & $\sqrt{ }$ & $\sqrt{ }$ & & & $\sqrt{ }$ & & & \\
\hline & 贝利黛眼蝶 Lethe baileyi & & & $\sqrt{ }$ & $\sqrt{ }$ & & & $\sqrt{ }$ & & & \\
\hline & 白带黛眼蝶 Lethe confusa & & $\sqrt{ }$ & $\sqrt{ }$ & & $\sqrt{ }$ & & & & & $\sqrt{ }$ \\
\hline & 圣母黛眼蝶 Lethe cybele & & & $\sqrt{ }$ & $\sqrt{ }$ & & & $\sqrt{ }$ & & & \\
\hline
\end{tabular}


易浪, 董亚坤, 苗白鸽, 彭艳琼 (2021) 云南高黎贡山地区蝴蝶群落多样性. 生物多样性, 29, 950-959. https://www.biodiversity-science.net/CN/10.17520/biods.2020486

\begin{tabular}{|c|c|c|c|c|c|c|c|c|c|c|c|}
\hline \multirow{3}{*}{$\begin{array}{l}\text { 科名 } \\
\text { Family }\end{array}$} & \multirow{3}{*}{$\begin{array}{l}\text { 种类 } \\
\text { Species }\end{array}$} & \multicolumn{3}{|c|}{ 海拔 Altitude (m) } & \multicolumn{3}{|c|}{ 生境 Habitat } & \multicolumn{4}{|c|}{ 季节 Season } \\
\hline & & $<1000$ & $1000 \Omega$ & > 2000 & 保护区 & 边缘交错带 & 农业种植区 & 2019 & 2020 & 2020 & 2020 \\
\hline & & $-1,000$ & $1,000-2,000$ & 2,000 & Reservation & Ecotone & Farm & 秋季 & 春季 & 夏季 & 秋季 \\
\hline & 黛眼蝶 Lethe dura & & & $\sqrt{ }$ & $\sqrt{ }$ & & & $\sqrt{ }$ & & & \\
\hline & 深山黛眼蝶 Lethe insana & & & $\sqrt{ }$ & $\sqrt{ }$ & & & $\sqrt{ }$ & & & \\
\hline & 侧带黛眼蝶 Lethe latiaris & & & $\sqrt{ }$ & $\sqrt{ }$ & & & $\sqrt{ }$ & & & \\
\hline & 迷纹黛眼蝶 Lethe maitrya & & & $\sqrt{ }$ & $\sqrt{ }$ & & & $\sqrt{ }$ & & & $\sqrt{ }$ \\
\hline & 锯纹黛眼蝶 Lethe nicetas & & & $\sqrt{ }$ & $\sqrt{ }$ & & & $\sqrt{ }$ & & & \\
\hline & 波纹黛眼蝶 Lethe rohria & & $\sqrt{ }$ & & & $\sqrt{ }$ & & & & & $\sqrt{ }$ \\
\hline & 华山黛眼蝶 Lethe serbonis & & & $\sqrt{ }$ & $\sqrt{ }$ & & & & & & $\sqrt{ }$ \\
\hline & 西峒黛眼蝶 Lethe sidonis & & & $\sqrt{ }$ & $\sqrt{ }$ & & & & & & $\sqrt{ }$ \\
\hline & 玉带黛眼蝶 Lethe verma & $\sqrt{ }$ & $\sqrt{ }$ & & $\sqrt{ }$ & $\sqrt{ }$ & $\sqrt{ }$ & $\sqrt{ }$ & & & $\sqrt{ }$ \\
\hline & 暮眼蝶 Melanitis leda & & $\sqrt{ }$ & & & & $\sqrt{ }$ & & & & $\sqrt{ }$ \\
\hline & 拟稻眉眼蝶 Mycalesis francisca & $\sqrt{ }$ & $\sqrt{ }$ & & & $\sqrt{ }$ & & $\sqrt{ }$ & $\sqrt{ }$ & & $\sqrt{ }$ \\
\hline & 稻眉眼蝶 Mycalesis gotama & & $\sqrt{ }$ & & $\sqrt{ }$ & & & & & & $\sqrt{ }$ \\
\hline & 小眉眼蝶 Mycalesis mineus & & $\sqrt{ }$ & & $\sqrt{ }$ & & & & & $\sqrt{ }$ & \\
\hline & 密纱眉眼蝶 Mycalesis misenus & & $\sqrt{ }$ & $\sqrt{ }$ & $\sqrt{ }$ & $\sqrt{ }$ & & & & $\sqrt{ }$ & $\sqrt{ }$ \\
\hline & 䧗眼蝶 Ypthima balda & & $\sqrt{ }$ & & $\sqrt{ }$ & $\sqrt{ }$ & & & $\sqrt{ }$ & $\sqrt{ }$ & \\
\hline & 中华䇱眼蝶 Ypthima chinensis & $\sqrt{ }$ & $\sqrt{ }$ & & $\sqrt{ }$ & $\sqrt{ }$ & $\sqrt{ }$ & $\sqrt{ }$ & & & \\
\hline & 孔翟眼蝶 Ypthima confusa & & $\sqrt{ }$ & $\sqrt{ }$ & $\sqrt{ }$ & $\sqrt{ }$ & $\sqrt{ }$ & $\sqrt{ }$ & & & $\sqrt{ }$ \\
\hline & 幽蒦眼蝶 Ypthima conjuncta & & $\sqrt{ }$ & & & $\sqrt{ }$ & & $\sqrt{ }$ & & & \\
\hline & 连斑䇾眼蝶 Ypthima sakra & & $\sqrt{ }$ & $\sqrt{ }$ & $\sqrt{ }$ & $\sqrt{ }$ & & $\sqrt{ }$ & & $\sqrt{ }$ & $\sqrt{ }$ \\
\hline & 大波篗眼蝶 Ypthima tappana & & $\sqrt{ }$ & & $\sqrt{ }$ & & & & & & $\sqrt{ }$ \\
\hline & 卓矍眼蝶 Ypthima zodia & & $\sqrt{ }$ & & & $\sqrt{ }$ & & $\sqrt{ }$ & & & \\
\hline & 金斑蝶 Danaus chrysippus & $\sqrt{ }$ & & & & & $\sqrt{ }$ & $\sqrt{ }$ & & & \\
\hline & 虎斑蝶 Danaus genutia & $\sqrt{ }$ & $\sqrt{ }$ & & & $\sqrt{ }$ & $\sqrt{ }$ & $\sqrt{ }$ & & $\sqrt{ }$ & \\
\hline
\end{tabular}


易浪, 董亚坤, 苗白鸽, 彭艳琼 (2021) 云南高黎贡山地区蝴蝶群落多样性. 生物多样性, 29, 950-959. https://www.biodiversity-science.net/CN/10.17520/biods.2020486

\begin{tabular}{|c|c|c|c|c|c|c|c|c|c|c|c|}
\hline \multirow{3}{*}{$\begin{array}{l}\text { 科名 } \\
\text { Family }\end{array}$} & \multirow{3}{*}{$\begin{array}{l}\text { 种类 } \\
\text { Species }\end{array}$} & \multicolumn{3}{|c|}{ 海拔 Altitude (m) } & \multicolumn{3}{|c|}{ 生境 Habitat } & \multicolumn{4}{|c|}{ 季节 Season } \\
\hline & & \multirow{2}{*}{$<1,000$} & \multirow{2}{*}{$1,000-2,000$} & \multirow{2}{*}{$>2,000$} & \multirow{2}{*}{$\begin{array}{c}\text { 保护区 } \\
\text { Reservation }\end{array}$} & \multirow{2}{*}{$\begin{array}{c}\text { 边缘交错带 } \\
\text { Ecotone }\end{array}$} & \multirow{2}{*}{$\begin{array}{c}\text { 农业种植区 } \\
\text { Farm }\end{array}$} & \multirow{2}{*}{$\begin{array}{l}2019 \\
\text { 秋季 }\end{array}$} & \multirow{2}{*}{$\begin{array}{l}2020 \\
\text { 春季 }\end{array}$} & \multirow{2}{*}{$\begin{array}{l}2020 \\
\text { 夏季 }\end{array}$} & \multirow{2}{*}{$\begin{array}{l}2020 \\
\text { 秋季 }\end{array}$} \\
\hline & & & & & & & & & & & \\
\hline & 异型紫斑蝶 Euploea mulciber & $\sqrt{ }$ & $\sqrt{ }$ & $\sqrt{ }$ & $\sqrt{ }$ & $\sqrt{ }$ & $\sqrt{ }$ & $\sqrt{ }$ & $\sqrt{ }$ & & \\
\hline & 黑绢斑蝶 Parantica melanea & & & $\sqrt{ }$ & $\sqrt{ }$ & & & $\sqrt{ }$ & $\sqrt{ }$ & & \\
\hline & 大绢斑蝶 Parantica sita & & $\sqrt{ }$ & $\sqrt{ }$ & $\sqrt{ }$ & $\sqrt{ }$ & & $\sqrt{ }$ & $\sqrt{ }$ & $\sqrt{ }$ & $\sqrt{ }$ \\
\hline & 茥麻珍蝶 Acraea issoria & & $\sqrt{ }$ & & $\sqrt{ }$ & $\sqrt{ }$ & $\sqrt{ }$ & $\sqrt{ }$ & & & $\sqrt{ }$ \\
\hline 弄蝶科 & 黄斑银弄蝶 Carterocephalus alcinoides & & $\sqrt{ }$ & & & & $\sqrt{ }$ & & $\sqrt{ }$ & & \\
\hline \multirow[t]{10}{*}{ Hesperiidae } & 绿弄蝶 Choaspes benjaminii & & $\sqrt{ }$ & & & $\sqrt{ }$ & & & & & $\sqrt{ }$ \\
\hline & 中华捷弄蝶 Gerosis sinica & & $\sqrt{ }$ & & $\sqrt{ }$ & & & & & $\sqrt{ }$ & \\
\hline & 角翅弄蝶 Odontoptilum angulatum & & $\sqrt{ }$ & & $\sqrt{ }$ & & & & & & $\sqrt{ }$ \\
\hline & 隐纹谷弄蝶 Pelopidas mathias & $\sqrt{ }$ & & & & & $\sqrt{ }$ & $\sqrt{ }$ & & & \\
\hline & 台湾孔弄蝶 Polytremis eltola & & $\sqrt{ }$ & & & $\sqrt{ }$ & & $\sqrt{ }$ & & & \\
\hline & 孔子黄室弄蝶 Potanthus confucius & & $\sqrt{ }$ & & $\sqrt{ }$ & & & & $\sqrt{ }$ & & \\
\hline & 尖翅黄室弄蝶 Potanthus palnia & & $\sqrt{ }$ & & & & $\sqrt{ }$ & & & & $\sqrt{ }$ \\
\hline & 黄襟弄蝶 Pseudocoladenia dan & & $\sqrt{ }$ & & & $\sqrt{ }$ & & $\sqrt{ }$ & & & \\
\hline & 暗缘謏弄蝶 Sovia grahami & & & $\sqrt{ }$ & $\sqrt{ }$ & & & & & & $\sqrt{ }$ \\
\hline & 姜弄蝶 Udaspes folus & $\sqrt{ }$ & & & & & $\sqrt{ }$ & $\sqrt{ }$ & & & \\
\hline
\end{tabular}

、代表本研究在不同海拔、生境和季节中调查到的种类。 
易浪, 董亚坤, 苗白鸽, 彭艳琼 (2021) 云南高黎贡山地区蝴蝶群落多样性. 生物多样性, 29, 950-959. https://www.biodiversity-science.net/CN/10.17520/biods.2020486

附录4 云南高黎贡山地区濒危、保护蝴蝶物种名录

Appendix 4 List of endangered and protected butterfly species in Gaoligong region of Yunnan

\begin{tabular}{|c|c|c|c|c|c|}
\hline 序号 & 科 & 种类 & 拉丁名 & 中国物种 & 国家重点保护 \\
\hline \multirow[t]{3}{*}{ Number } & Family & Species & Latin names & 红色名录 & 野生动物名 \\
\hline & & & & China Species & List of Key Protected \\
\hline & & & & Red List & Wild Animals in China \\
\hline 1 & 粉蝶科 & 三黄绢粉蝶 & Aporia larraldei & NT & \\
\hline 2 & Pieridae & 隐条斑粉蝶 & Delias subnubila & NT & \\
\hline 3 & & 黄裙斑粉蝶 & Delias wilemani & NT & \\
\hline 4 & & 鹤顶粉蝶 & Hebomoia glaucippe & NT & \\
\hline 5 & & 斑缘菜粉蝶 & Pieris deota & NT & \\
\hline 6 & & 锯粉蝶 & prioneris thestylis & NT & \\
\hline 7 & 凤蝶科 & 多尾凤蝶 & Bhutanitis lidderdalii & VU & 二级 \\
\hline 8 & Papilionidae & 鹿风蝶 & Byasa alcinous & VU & \\
\hline 9 & & 达摩麇凤蝶 & Byasa daemonius & VU & \\
\hline 10 & & 云南麝凤蝶 & Byasa hedistus & VU & \\
\hline 11 & & 纨裤鹿凤蝶 & Byasa latreillei & VU & \\
\hline 12 & & 突缘鹿凤蝶 & Byasa plutonius & VU & \\
\hline 13 & & 燕凤蝶 & Lamproptera curius & NT & \\
\hline 14 & & 窄斑翠凤蝶 & Papilio arcturus & NT & \\
\hline 15 & & 圆翅剑凤蝶 & Pazala parus & NT & \\
\hline 16 & & 乌克兰剑凤蝶 & Pazala tamerlana & NT & \\
\hline 17 & & 嗀凤蝶 & Teinopalpus imperialis & VU & 二级 \\
\hline 18 & & 金裳凤蝶 & Troides aeacus & NT & 二级 \\
\hline 19 & 灰蝶科 & 美丽彩灰蝶 & Heliophorus pulcher & VU & \\
\hline 20 & Lycaenidae & 点染燕灰蝶 & Rapala suffusa & NT & \\
\hline 21 & & 曲带褐蚬蝶 & Abisara abnormis & NT & \\
\hline 22 & & 方裙褐蚬蝶 & Abisara freda & NT & \\
\hline 23 & & 红秃尾蚬蝶 & Dodona adonira & NT & \\
\hline 24 & & 大斑尾蚬蝶 & Dodona egeon & NT & \\
\hline 25 & & 喇嘛小蚬蝶 & Polycaena lama & NT & \\
\hline 26 & 蛱蝶科 & 姹蛱蝶 & Chalinga elwesi & NT & \\
\hline 27 & Nymphalidae & 窗蛱蝶 & Dilipa morgiana & NT & \\
\hline 28 & & V纹翠蛱蝶 & Euthalia alpheda & NT & \\
\hline 29 & & 珐琅翠蛱蝶 & Euthalia franciae & NT & \\
\hline 30 & & 链斑翠蛱蝶 & Euthalia sahadeva & NT & \\
\hline 31 & & 缕蛱蝶 & Liting a cottini & NT & \\
\hline 32 & & 拟缕蛱蝶 & Litinga mimica & NT & \\
\hline 33 & & 德环蛱蝶 & Neptis dejeani & NT & \\
\hline 34 & & 五段环蛱蝶 & Neptis divisa & NT & \\
\hline 35 & & 森环蛱蝶 & Neptis nemorum & VU & \\
\hline 36 & & 泰环蛱蝶 & Neptis thestias & VU & \\
\hline
\end{tabular}


易浪, 董亚坤, 苗白鸽, 彭艳琼 (2021) 云南高黎贡山地区蝴蝶群落多样性. 生物多样性, 29, 950-959. https://www.biodiversity-science.net/CN/10.17520/biods.2020486

\begin{tabular}{|c|c|c|c|c|c|}
\hline 序号 & 科 & 种类 & 拉丁名 & 中国物种 & 国家重点保护 \\
\hline \multirow[t]{3}{*}{ Number } & Family & Species & Latin names & 红色名录 & 野生动物名 \\
\hline & & & & China Species & List of Key Protected \\
\hline & & & & Red List & Wild Animals in China \\
\hline 37 & & 云南环蛱蝶 & Neptis yunnana & VU & \\
\hline 38 & & 大紫蛱蝶 & Sasakia charonda & NT & \\
\hline 39 & & 细眉林眼蝶 & Aulocera merlina & NT & \\
\hline 40 & & 棕带眼蝶 & Chonala praeusta & NT & \\
\hline 41 & & 安徒生黛眼蝶 & Lethe andersoni & NT & \\
\hline 42 & & 圣母黛眼蝶 & Lethe cybele & NT & \\
\hline 43 & & 宽带黛眼蝶 & Lethe helena & NT & \\
\hline 44 & & 甘萨黛眼蝶 & Lethe kansa & NT & \\
\hline 45 & & 迷纹黛眼蝶 & Lethe maitrya & NT & \\
\hline 46 & & 玉山黛眼蝶 & Lethe niitakana & VU & \\
\hline 47 & & 华山黛眼蝶 & Lethe serbonis & VU & \\
\hline 48 & & 西峒黛眼蝶 & Lethe sidonis & VU & \\
\hline 49 & & 素拉黛眼蝶 & Lethe sura & NT & \\
\hline 50 & & 华西白眼蝶 & Melanargia leda & NT & \\
\hline 51 & & 珞巴眉眼蝶 & Mycalesis lepcha & NT & \\
\hline 52 & & 田园荫眼蝶 & Neope agrestis & NT & \\
\hline 53 & & 网纹荫眼蝶 & Neope christi & NT & \\
\hline 54 & & 黑斑荫眼蝶 & Neope pulahoides & NT & \\
\hline 55 & & 拟网纹荫眼蝶 & Neope simulans & NT & \\
\hline 56 & & 黄网眼蝶 & Rhaphicera satrica & VU & \\
\hline 57 & & 重光篗眼蝶 & Ypthima dromon & VU & \\
\hline 58 & & 台湾襍眼蝶 & Ypthima formosana & VU & \\
\hline 59 & & 融斑襍眼蝶 & Ypthima nikaea & NT & \\
\hline 60 & & 连斑矍眼蝶 & Ypthima sakra & NT & \\
\hline 61 & & 黑虎斑蝶 & Danaus melanippus & NT & \\
\hline 62 & & 西藏绢斑蝶 & Parantica pedonga & NT & \\
\hline 63 & & 白兒箭环蝶 & $\begin{array}{l}\text { Stichophthalma } \\
\text { fruhstorferi }\end{array}$ & NT & \\
\hline 64 & 弄蝶科 & 橙翅伞弄蝶 & Bibasis jaina & NT & \\
\hline 65 & Hesperiidae & 尖翅椰弄蝶 & Gangara lebadea & NT & \\
\hline 66 & & 曲纹带弄蝶 & Lobocla germana & NT & \\
\hline 67 & & 黄带弄蝶 & Lobocla liliana & NT & \\
\hline
\end{tabular}

参照《中国物种红色名录(第三卷): 无脊椎动物》 (汪松和解炎, 2005)核定的濒危等级: 近危 (Near Threatened, NT)、易危物种(Vulnerable, VU), 以及2021年2月国家林业和草原局、农业 农村部发布的《国家重点保护野生动物名录》评估保护级别。 